\title{
Legality, Bureaucracy, and Class in the Welfare System
}

\author{
William H. Simon†
}

When lawyers confronted the welfare system in the 1960 's, they charged it with oppressive moralism, personal manipulation, and invasion of privacy. They focused attention on the "man-in-the-house" rules that disqualified families on the basis of the mother's sexual conduct and the "midnight raids" in which welfare workers forced their way into recipients' homes searching for evidence of cohabitation. ${ }^{1}$

When I represented welfare recipients from 1979 to 1981, the workers showed little interest in policing their morals or intruding on their private lives. The "man-in-the-house" rule and the practice of unannounced or nighttime visits had been repudiated. ${ }^{2}$ Yet the pathologies emphasized by the lawyers of the 1960's seemed to have been mitigated at the cost of exacerbating others that were in some respects their mirror images: indifference, impersonality, and irresponsibility. The new pathologies were typified by cases in which newly arrived Cuban refugees were denied assistance because they could not produce appropriately certified copies of birth certificates for their children or in which people who sought assistance from the wrong worker were sent away without explanation, thinking mistakenly that they were entitled to nothing.

I have a particularly vivid memory of a woman whose grant was terminated when she failed to produce a recently dated letter from the school of one of her children verifying his enrollment. She had produced letters from the three other schools her children attended and had produced let-

$\dagger$ Assistant Professor of Law, Stanford University. This essay arises from my practice at the Legal Services Institute, Boston, Massachusetts, from 1979 to 1981 and from conversations with my colleagues there, especially Evelyn Brodkin, Duncan Kennedy, Michael Lipsky, and Teresa Nelson. Many other friends and colleagues gave valuable advice and assistance. Theodore Marmor, Deborah Rhode, and Richard Scott were especially generous. I am distinctively indebted to Jerry Mashaw and Joel Handler for their encouragement of my attempt to criticize (as well as to appropriate from) their work. Research for the essay was supported by the Stanford Legal Research Fund, made possible by a bequest from the estate of Ira S. Lillick and by gifts from other friends of the Stanford Law School.

1. See Reich, Midnight Welfare Searches and the Social Security Act, 72 YALE L.J. 1347 (1963); Sparer, The Place of Law in Social Work Education, 17 BUfFalo L. REV. 733, 734-37 (1968).

2. See King v. Smith, 392 U.S. 309 (1968); U.S. DEP'T OF HEALTH, EDUC. \& WELFARE, HAND. BOOK OF PUBLIC ASSISTANCE ADMINISTRATION pt. IV, $\$ \S 2200(a), 2300$ (1967). Some inquiry about personal matters still occurs. Establishing economic eligibility requires information about financial affairs, and this sometimes involves inquiry into sexual relations, for example, in connection with the establishment of paternity for the purpose of enforcing support obligations. But both the scope and frequency of such inquiries has sharply diminished. 
ters from all four schools on three prior occasions within the preceeding six months. But this time she was unable to get the letter from one school because it was August, and the school office was closed. After the school office opened, she brought the letter to her worker, who responded that it was too late: "There is nothing I can do." What she meant (as she explained to me later after the woman's checks had stopped) was that there was nothing she, as an "ongoing" case worker, could do but that the recipient could have been immediately reinstated simply by filing an application with the "intake" unit. If the literary personification of the pathologies of the old regime was Dostoyevsky's Grand Inquisitor, with his relentless intimacy and psychological omnipotence, the personification of the pathologies of the new regime is Kafka's Doorkeeper, who stands, passive and inscrutable, before the door to the Law and announces only when it is too late, "this door was intended for you. I am now going to shut it."3

Of course, one should not appraise a system solely in terms of its worst cases. Such horror stories are merely the more dramatic and disturbing manifestations of a series of related developments I want to discuss. For better or worse (and I don't intend to argue it has been only for worse), the welfare system has been transformed in the past two decades. Lawyers and legal ideas have played a central role in this transformation. Since the 1960 's, the social work profession has ceded to the professions of law and management both its ideological custody of the welfare system and its preeminent role in its administration. The concerns of law and management have converged in the three basic themes of the recent literature and practice of welfare administration: first, the formalization of entitlement, by which I mean the formulation of the eligibility norms as rules; second, the bureaucratization of administration, by which I mean the intensification of formally hierarchical organization; and third, the proletarianization of the work force, by which I mean the diminution of the status, skill, education, and reward associated with the frontline welfare worker's job.

This essay examines the relation of contemporary legal discourse to these institutional and social developments. Part I illustrates the developments with a discussion of the largest and most controversial cash public assistance program, Aid to Families with Dependent Children (AFDC). Part II discusses the legal doctrines with which these developments have been explained, promoted, and criticized. These doctrines take the form of a kind of sociological jurisprudence that proceeds by linking certain basic social goals with a particular style of legality and in turn with a particular form of organization. The version of this approach that has most influ-

3. F. KAFKA, THE TRIAL 269 (Vintage ed. 1969). 
enced the welfare system holds that the goals of efficiency, freedom, and fairness require a legality of formality which in turn requires a hierarchical enforcement organization staffed at the lower tier by a proletarian work force. I argue that this doctrine is implausible, at least on the level of abstraction at which it has influenced welfare reform, and that it has tended to obscure some of the problems that have attended the transformation of the system. While the great virtue of recent legal writing on the welfare system has been to focus attention on the relation of legality to organization, its failing has been to blur important sociological and political questions by (often in spite of the expressed intentions of the authors) treating them as legal questions. Part III sketches an alternative account of the welfare system that attempts to do justice to social context and political contingency.

Although its primary purposes are historical and critical, there is a prescriptive theme running through this essay. I suggest that a vision of legality and organization opposed to the dominant vision is more plausible as an ideal and as a guide to reform in welfare administration. This opposed vision involves a legality of relative informality, a decentralized enforcement structure, and a corps of enforcers with some of the attributes of skill, education, and status associated with professionalism. This vision is in many respects similar to the understanding of welfare legality and enforcement of the New Deal social workers who founded the modern public assistance system. ${ }^{4}$ Although the argument for the opposed vision remains speculative and inconclusive, it attempts to clarify the basic issues by linking the contest between the dominant and opposed visions to larger social and political issues. I argue that the choice between the competing visions depends on the resolution in theory and practice of a central tension in the understanding of class implicit in sociological jurisprudence and in much contemporary legal scholarship.

\section{The Transformation of Public Assistance}

The trends of formalization, bureaucratization, and proletarianization in public assistance are exemplified by the recent history of the AFDC program. I use AFDC, and particularly the Massachusetts AFDC program, as my principal example for reasons of convenience-I've had personal experience with it, and it is described in a variety of available materials. But other considerations also make AFDC an appropriate focus. Despite anachronistic eligibility limitations that exclude most indigent

4. Although the social workers and their program have been blamed for the pathologies of welfare administration, the charge is unfair. In fact their approach has never fairly been tried. See infra pp. 1214-16; Simon, The Invention and Reinvention of Welfare Rights, 44 MD. L. REV. (1984) (forthcoming). 
two-parent families, AFDC is the central pillar of the American public assistance system. It is the largest cash assistance program and the one on which intense and conflicting popular attitudes toward welfare tend to focus. At the level of initial determination, it is normally administered by the state welfare departments in close conjunction with one of the two other major cash assistance programs, General Assistance, and with the two major in-kind assistance programs, Food Stamps and Medicaid." Most of the developments in AFDC have either directly affected these programs or correspond to analogous developments in them. There have also been analogous developments in Supplemental Security Income, the cash public assistance program for the aged, blind, and disabled administered by the Social Security Administration, and the two largest cash social insurance programs, Social Security, and Unemployment Insurance.

\section{A. Developments}

Here are the more notable instances of the three overlapping trends of formalization, bureaucratization, and proletarianization in AFDC:

The Reformulation of Substantive Norms. The substantive eligibility norms have been revised to increase their substantive formality, that is, to give them the form of rules rather than of standards. ${ }^{6}$ There are three aspects to this distinction.

First, rules are more explicit than standards. During the period from 1935 to the early 1960 's, which I call the old regime, promulgated regulations and published norms of any kind were brief. Workers were expected to absorb some aspects of the eligibility criteria through experience on the job and to have learned other aspects previously through education or experience in the community. The reforms of the past two decades have sought to make the criteria as explicit as possible. Statutes and regulations have become more voluminous and detailed, and they have been supplemented by still more voluminous instructional manuals that attempt to explicate them.

5. AFDC is the creature of Title IV of the Social Security Act of 1935 and subsequent amendments. 42 U.S.C. $\$ \S 601-615$ (1976 \& Supp. V 1981). The Act creates a system of federal grants to the states for programs formulated and administered by them but subject to federal statutory and regulatory restrictions and to the supervision of the Secretary of Health and Human Services (HHS). (For convenience, I refer throughout this essay to the agency's predecessors by its current name.) The federal government reimburses the states for expenditures under their programs at rates that average about 55\%. In 1980, there were 11.1 million recipients, and expenditures totaled $\$ 12.5$ billion. Current Operating Statistics, SOC. SECURITY BULL., Sept. 1982, at 43-44. For a history of the program up to 1974, see Lurie, Major Changes in the Structure of the AFDC Program Since 1935, 59 COR. NELL L. REV. 825 (1974); for an overview of the American income maintenance system, see S. LEVITAN, PROGRAMS IN AID OF THE POOR FOR THE 1980S (3d ed. 1980).

6. On formality and the distinction between rules and standards, see Kennedy, Form and Substance in Private Law Adjudication, 89 HARV. L. REV. 1685 (1976). 
Second, rules constrain judgment more than standards by limiting the number of factors to be considered in decisionmaking. Standards tend to declare a general social goal or value and direct the decisionmaker to take the action most consistent with it in the light of all relevant circumstances. They tend to permit an individualized assessment of how goals or values can be implemented in the circumstances of the particular case. Rules, on the other hand, tend to permit consideration of relatively few specified factors. They are over- and under-inclusive in regard to their purposes. The trend toward formalization can be seen in the elimination of many norms that invoked general language and made relevant a wide variety of factors. The best known instances are the "suitable home" regulations and others that required in very general language determinations of the adequacy of the applicant as a parent and homemaker. ${ }^{8}$ Other instances involve the consideration of the claimant's income and assets. For example, a provision that a car not be counted as a potentially disqualifying asset if it is "needed" by the applicant has been replaced by one providing that ownership of a car not be counted if its value is less than $\$ 1500$. A provision requiring that earned income not be counted to the extent offset by expenses "reasonably attributable" to the earnings has been replaced by one requiring that $\$ 75$ per month be disregarded as an expense allowance. ${ }^{\circ}$

In the late 1960's and early 1970's most states restructured their AFDC budgeting norms to eliminate many specific circumstances of need that were previously considered in determining eligibility. Prior to this "consolidation" of need standards, AFDC grants typically took some account of the actual cost to the particular applicant of items such as shelter and fuel (as opposed to making a uniform allowance to all applicants), of the age of the recipients (families with older children got higher grants), and of a variety of "special" recurring or non-recurring needs. For example, an applicant without a washing machine might receive a supplement for laundry expenses; a diabetic might receive a supplement for the extra food expenses of a restrictive diet; a new baby might receive a crib; a recipient whose check has been stolen might receive a replacement grant. Consolidation eliminated many such factors and moved state programs toward a uniform need standard based only on the size of the family..$^{10}$ Analogous

7. Id. at $1687-89$.

8. See W. BELL, AID TO DEPENDENT CHILDREN (1965).

9. Chief, Need Determination in AFDC Programs, SCC. SEcuRITY BuLL., Sept. 1979, at 11, 18 n.4 (prior automobile rules); 45 C.F.R. \& 233.20(a)(2)(xiv)(A) (1983) (current automobile rule); Shea v. Vialpando, 416 U.S. 251 (1974) (prior earned income rule); 42 U.S.C. § 602(a)(8)(A)(ii) (Supp. V 1981) (current earned income rule).

10. URBAN SYSTEMS RESEARCH \& ENGINEERING, AFDC STANDARDS OF NEED: AN EVALUATION OF CURRENT PRAGTICES, ALTERNATIVE APPROACHES, AND POLICY OPTIONS 174-246 (report prepared 
developments on the income side of the budget have eliminated consideration of factors regarding the applicant's living arrangements. For example, a variety of norms requiring consideration of the financial benefit to recipients of the income or expenditures of non-recipient household members has been eliminated.11

Another manifestation of this aspect of formalization is the development of various sub-legal instructional materials that purport to break down the prescriptions of the promulgated law into still more precise operations. For example, the instructions that operationalize a regulation providing that the applicant's monthly income be deducted from the need standard might set out a form and instruct the worker to enter the need standard on line a of the form, to enter the amounts shown on the applicant's pay stubs for the three most recent weeks on line $b$, to add these amounts and enter the total on line $c$; to divide the total on line $c$ by 3 and enter the quotient on line $d$; to multiply the amount on line $d$ by 4.3 and enter the product on line $e$, and to subtract from the amount on line a the amount on line $e .^{12}$

The third aspect of the formalization of substantive norms concerns the style of judgment and the attitude prescribed for the decisionmakers. The old regime aspired to inculcate a capacity for complex interpretative judgment based on an understanding of the fundamental purposes of the program. Work was conceived as direct participation in the elaboration and implementation of important social goals. Mechanical judgment and literalistic interpretation were discouraged. ${ }^{13}$ The formalization of recent years repudiates this ideal and embraces mechanical judgment and literalistic

for SSA, Aug. 1980); see Rosado v. Wyman, 304 F. Supp. 1356, 1365-69 (S.D.N.Y.), rev'd, 414 F.2d 170 (2d Cir. 1969), rev'd, 397 U.S. 397 (1970).

A variety of separate "special need" programs remain, but they are generally marginal both in coverage and funding. They have been strained in recent years as a consequence of both the elimination of specialized coverage in AFDC and funding cutbacks. See J. HANDLER \& M. SOSIN, LAST RESORTS: MEETING EMERGENCY NEEDS IN PUBLIC ASSISTANCE (1983).

The trend toward formalization has been partially offset by the recent growth of "in kind" medical and education programs that require complex, informal judgments regarding the particular needs of the applicant. Within the welfare system, Medicare and Medicaid are the most important instances. However, these programs are structured so that such judgments are not made within the welfare administration but are delegated to medical professionals outside the administration.

11. See Van Lare v. Hurley, 421 U.S. 338 (1975); Lewis v. Martin, 397 U.S. 552 (1970). These cases have spawned a large body of litigation further restricting consideration of variations in living arrangements. See, e.g., Leone v. Blum, 73 A.D.2d 254, 425 N.Y.S.2d 836 (1980), af'd sub nom. Delmar v. Blum, 53 N.Y.2d 105, 423 N.E.2d 27, 440 N.Y.S.2d 604 (1981). The 1981 and 1982 AFDC amendments, which partially reintroduce factors eliminated by Lewis and Van Lare, are partial retreats from the trend toward simplification. 42 U.S.C. $\S \S 602(a)(31), 612$, as amended by Pub. L. No. 97-35, § 2306(a) (1981), and Pub. L. No. 97-248, § 155 (1982).

12. The example is based on my memory of provisions of the Massachusetts AFDC Worker Handbook in effect in 1980.

13. See FEDERAL SECURITY AGENCY, COMMON HUMAN NEEDS: AN INTERPRETATION FOR STAFF IN PUBLIC ASSISTANCE AGENCIES 104-22 (1945). 
interpretation. At the same time, it implicitly prescribes an attitude of impersonality. It seeks to alienate the worker from the purposes of the norms she enforces. There are two versions of this alienation; in one the worker is unaware of the purposes underlying the norms she enforces; in the other the worker feels bound to apply the norms in spite of their purposes. For example, consider a worker applying the instructions regarding income averaging in the preceding paragraph to an applicant who works only three weeks a month. The instructions, in effect, require the determination of a monthly average on the basis of the three most recent weekly pay stubs. If the immediate purpose of specifying three stubs is to spare the recipient the burden of having to produce more than three (or the welfare department the burden of having to store more than three) and the basic purpose of the entire set of instructions is to produce an estimate of the applicant's monthly earnings (which is what everyone interprets the regulations and statute to require), following the instructions literally in the case of a recipient who works only three weeks a month will result in violating the basic purpose by overstating the applicant's monthly income and thus understating the proper grant. When the client appeals to the basic purpose and argues that the grant is too low, the worker's response will depend on which version of alienation applies. Either he will feel that the client's claim is meaningless or irrelevant to his work or he will recognize the situation as one in which the system requires him to violate one of its basic purposes in the interest of formality. ${ }^{14}$

A cumulative effect of the three aspects of formality is that the system appears to require fewer and simpler substantive judgments and to require less information from the client about her personal circumstances. Another effect is that assistance is less sensitive to the circumstances of the applicant. $^{18}$

The Reconception of Proof. Under the old regime, the dominant view of the fact-finding phase of the eligibility process focused on the worker's

14. This example comes from a case described to me by Duncan Kennedy, who represented the recipient. The worker was aware that his action violated the purpose and language of the regulation but believed he was constrained by the handbook instruction.

15. The second and third aspects of formalization are notably exemplified in recent developments in the disability components of the Social Security and Supplemental Security Income programs. The Social Security Administration (SSA) has always provided lengthy and explicit statements of eligibility norms to front line workers. However, these statements have tended to take the form of the elaboration of standards through general interpretative principles and illustrative hypotheticals rather than specific instructions. In recent years, the Administration has revised its instructions to restrict the considerations bearing on the determinations and to foster more simplified and mechanical judgment. As the Administration acknowledges, the new rules frequently require denial of claims that a purposive interpretation based on the more standard-like norms of the statute and regulations would allow. The intention to replace complex judgment with routine mechanical operations is expressed in the change of the title of the instructions from "Claims Manual" to "Program Operating Manual System." See The Bellmon Report, SOC. SECURITY BuLl., May 1982, at 3, 8, 11-17. 
assessment of the credibility of the claimant's oral statements. The worker was expected to make an extensive and active investigation through office interviews of the claimant and visits to her home. He was to accord the claimant a strong presumption of credibility. When doubts arose, the worker was expected to undertake inquiry of employers, friends, or relatives. ${ }^{16}$ The presumption of credibility was often violated and states required applicants to document some statements prior to the 1960's. Nevertheless, as recently as 1969, the Department of Health and Human Services (HHS) proposed that states require workers to determine eligibility on the basis of the applicant's statements unless the statements were "incomplete, unclear, or inconsistent, or . . other circumstances in the particular case indicate to a prudent person that further inquiry should be made, and the individual cannot clarify the situation . . .."17

Since then, however, this view has been rejected in favor of one that emphasizes the claimant's responsibility for verifying eligibility through documents and that portrays the worker's role as passively policing the claimant's compliance with documentation requirements. Verification requirements have increased to require documentation of almost every factor bearing on eligibility. The Massachusetts welfare department gives applicants a list of thirty documents that they may be asked to supply. The typical applicant is required to produce about half that number and to do so must undertake dealings with about five or six bureaucracies other than the welfare department. ${ }^{18}$ At the same time, the frequency with which recipients must re-establish eligibility and renew much of the documentation has been increased to at least two and occasionally as often as five times a year. ${ }^{19}$ Many of the documents must meet stringent technical requirements. For example a letter verifying a child's enrollment at school

16. See FEDERAL SECURITY AGENCY, supra note 13, at vii, 22-23; 2 G. ABBOTT, THE CHILD AND THE STATE 238 (1938); Towle, Social Work: Cause and Function, in CHaRLOTTE TOWLE ON SOGIAL WORK AND SOCIAL CASEWORK 31 (H. Perlman ed. 1969); Note, Rehabilitation, Investigation and the Welfare Home Visit, 79 YALE L.J. 746, 746-51 (1970).

17. Methods for Determination of Eligibility, 34 Fed. Reg. 1145 (1969); see Note, Eligibility Determinations in Public Assistance: Selected Problems and Proposals for Reform in Pennsylvania, 115 U. PA. L. REV. 1307 (1967).

18. For example, the applicant may have to deal with the Bureau of Vital Statistics to get birth certificates; the SSA to get Social Security numbers; the welfare department's office of child support enforcement, the prosecutor's office, and the courts in connection with her obligation to assist the state in collecting support payments from an absent parent; the employment security department in order to register for the Work Incentive (WIN) program; other welfare bureaucracies in order to verify applications for all benefits she may be eligible for; her children's schools in order to verify their enrollment; her employer in order to verify her wages; her landlord and utility company in order to verify rent and utility payments; and a variety of institutions in order to verify the absence of a parent from the home. See Guttman, The Application Process, in CONG. RESEARCH SERV. REP. TO HOUSE COMM. ON GOV'T OPERATIONS, 95TH CONG., 1ST SESS., ADMINISTRATION OF THE AFDC PROGRAM 30-84 (Comm. Print 1977).

19. Federal regulations require redetermination at least every six months. 45 G.F.R. $\S$ 206.10(d)(9)(iii) (1983). More frequent redeterminations are made for cases considered "error prone." 
may be rejected if not signed by the right official or not dated within the appropriate number of days. The workers are encouraged through training and supervision to insist on strict compliance with the documentation rules, and they are discouraged from relying on the claimant's undocumented statements even when the rules do not expressly require documentation. (This does not invariably work to the disadvantage of the claimant. For a few months during 1980, Boston welfare workers believed-even though the regulations did not so provide-that they could not reduce or terminate a grant on the basis of an orally reported increase in wages until the increase had been documented by the pay stubs for three successive weeks.) Even a well-educated person (which most claimants are not) without specialized knowledge of the system would not be able to satisfy the documentation requirements without extensive explanation, and in some instances, active assistance. ${ }^{20}$ Although many states purport to require the workers to provide such explanation and assistance, as we will see, relatively little effort is made to enforce these requirements.

The changed approach to proof has formalized fact-finding in a manner analogous to the way the substantive norms have been formalized. At the same time, it has increased the burden on recipients of paper-pushing and bureaucratic hoop-jumping.

The Advent of Quality Control. Another important development is the change in the character of organizational review and supervisory procedures. Under the old regime, two such procedures were emphasized. One was relatively constant and direct personal supervision of the worker by a supervisor in the same office. The relationship was conceived as a collegial one between professionals, albeit professionals of unequal experience and authority. Supervision involved both review of written case records by the supervisor and oral consultation in which the supervisor explained her judgments and the worker was encouraged to participate actively and respond to the supervisor's comments. The goal was an informal consensus regarding the appropriate disposition of the case. The process was supposed to involve an intense scrutiny of both the applicant's situation and the worker's response to it. ${ }^{21}$ In practice, supervision appears to have been

20. An Urban Institute Study underscores the importance of advice and assistance to claimants by comparing a "client accessibility index" for each state with the average educational level of recipients in the state. The accessibility index is a function of the percentage of denials and terminations on "procedural" (including documentation) grounds, underpayment errors as a percentage of caseload and payments, and the percentage of applications processed late. The study finds, "the lower the average educational levels of AFDC clients, the lower was the index accessibility," and "the higher the proportion of Spanish-speaking clients in a state, the lower its accessibility." M. BENDICK, A. LAVINE \& T. CAMPBELL, THE ANATOMY OF AFDC ERRORS 58-60 (1978).

21. See FEDERAL SECURITY AGENGY, supra note 13, at 95-122; V. ROBINSON, SUPERVISION IN SOCIAL CASE WORK (1936). 
more authoritarian and summary than this ideal. ${ }^{22}$ Nevertheless, as the basic method of organizational review, it made for relatively complex judgment and decentralized administration. Review was done by a person with extensive knowledge of the worker, the case, and the immediate context of decision, and it was done in a manner facilitating participation by the worker.

Supervision was supplemented by a variety of procedures, the most important of which was the federal audit. Periodically, HHS would review the records of a sample of the caseload. It would disallow reimbursement for the federal share of improper payments to the reviewed cases. When the review disclosed a pattern of mistake or lawlessness, HHS pressed the state to change its policy and instruct its workers appropriately. Efforts to affect the program through the audit appear to have been largely concerned with major policy matters. ${ }^{23}$

Beginning in the 1960's, the federal audit was supplemented and eventually replaced by procedures called Quality Control. Aside from their zealous invocation of the jargon of business management, the new procedures differ from the old in three respects. First, they use statistical methods to designate the sample of cases for review and to derive from the reviews an estimate of the total number of the state's cases and the total amount of its payments in "error." Second, since 1973, these estimates have been backed by the threat of "fiscal sanctions" in the form of withheld federal reimbursement for a portion of the estimated erroneous payments in the entire caseload, not just the cases reviewed. Third, Quality Control involves a more intensive and detailed review of the sample cases than the old procedures. In response to the federal system, the states have developed their own supplementary quality control processes, which make similar but less intensive reviews of larger samples of cases. These supplementary reviews are designed to lower error rates in advance of the federal reviews. ${ }^{24}$

22. See Scott, Professional Employees in a Bureaucratic Structure: Social Work, in THE SEMIPROFESSIONS AND THEIR ORGANIZATION 82, 102-10 (A. Etzioni ed. 1969).

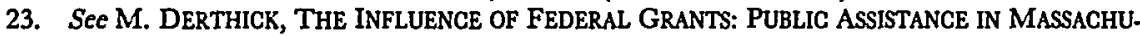
SETTS (1970).

24. See Richardson, Quality Control Efforts in Administration of the AFDC Program, in CONG. RESEARCH SERV. REP. TO HOUSE COMM. ON GOV'T OPERATIONS, supra note 18, at 202-05; Pratt, State Agencies Can Be Managed: The Massachusetts Experience with AFDC Error Rates, NEW ENG. J. HUM. SERV., Spring 1981, at 20. The regulations governing AFDC Quality Control appear at 45 C.F.R. $\S 205.40$ (1983). On the emergence of similar procedures in other programs, see $H E W$ Eftorts to Reduce Errors in Welfare Programs (AFDC and SSI): Hearings Before the Subcomm. on Oversight of the House Ways \& Means Comm., 94th Cong., 2d Sess. (1976) [hereinafter cited as HEW Efforts]; J. HANDLER, PROTECTING THE SOCIAL SERVICES CLIENT 101-16 (1979); M. MCDONALD, FOOD, STAMPS, AND INCOME MAINTENANCE 39-43 (1977); Chassman \& Rolston, Social Security Disability Hearings: A Case Study in Quality Assurance and Due Process, 65 CORNELL L. REV. 801 (1980). 
The new procedures have fueled both public and professional rhetoric about welfare in recent years, and in states with high error rates threatened with large fiscal sanctions, they have become the dominant influence on welfare administration. Reports of high error rates-federal Quality Control found $41 \%$ of all AFDC cases and $17 \%$ of all expenditures in error in $1973^{25}$ - have confirmed hostile views among legislators, the media, and the public about the system's beneficiaries and the people who run it and have been taken as evidence warranting cutbacks. ${ }^{28}$ At the same time, administrators, having committed large amounts of resources in response to Quality Control, have cited the consequent reductions in error as evidence of improvement in the system. ${ }^{27}$

There is, however, good reason to doubt these intepretations of Quality Control. To a large extent, Quality Control has obfuscated discussion of welfare administration by propagating a question-begging rhetoric of "error" to promote reforms that often could not survive reflective analysis. Many of the errors reported by Quality Control simply represent disagreements between reviewers and initial decisionmakers over the interpretation of ambiguous legal norms (is money paid for child care to a relative who would care for the child for free an "expense" deductible from earnings?) or ambiguous evidence (is a father reported by the recipient to be no longer residing at home but recently seen there on two occasions by a neighbor "absent" from the home?).

Many more of the error designations are undisputed but have been discovered only because the reviewer has used a different, more expensive procedure than the initial decisionmaker. A reviewer who makes more lengthy investigations is likely to discover errors, but such errors prove little about the reasonableness of the initial decisions, which depend in part on the ex ante appropriateness of devoting additional resources to the investigation. The fallacy of equating Quality Control errors with bad initial decisionmaking and error reduction with improved decisionmaking

25. See Richardson, supra note 24 , at 218 .

26. In 1978, Congressman Michel proposed to cut $\$ 1$ billion from HHS on the ground that at least that amount represented erroneous payments under welfare programs. The amendment was enacted but proved inconsequential because HHS was able at year end to make up the deficiency through fiscal maneuvering. Since then, Congress has enacted a series of provisions mandating fiscal sanctions for states failing to meet designated error reduction targets. To date, no sanctions have been imposed, in part because the states have had success in meeting the targets, in part because the Secretary has exercised the power to waive the sanctions. See G. Mills, Quality Control in Welfare Administration: An Analysis of Payment Error in Aid to Families with Dependent Children 56-64 (unpublished Harvard University Ph.D. dissertation 1981).

The current provision, which denies reimbursement for erroneous payments exceeding $4 \%$ in fiscal year 1984, appears at 42 U.S.C. $\$ 603$ (i) (Supp. V 1981). In 1982, the Reagan Administration proposed denying funds for the federal share of all payments found in error. Reagan's Bid for Zero Error Rate Encounters Skepticism in the States, AMERICAN PUBLIC WELFARE ASSOCIATION W-MEMO, Apr. 1982, at 1.

27. See Pratt, supra note 24. 
has recently been emphasized by a study concluding that half of the decline in the national AFDC overpayment error between 1975 and 1977 from $11.2 \%$ to $8.7 \%$ is attributable to nothing more than an increase in the caseloads of quality control reviewers during this period: when cases increased, the reviewers spent less time on each case and hence found fewer errors. ${ }^{28}$

Still a further portion of Quality Control errors consists of "paper errors," formal procedural omissions that when remedied do not affect the amount of the grant and often provide little benefit to the program. For example, in 1978, HHS decided to count as erroneous all payments to recipients who appeared not to have applied for Social Security cards or registered for the Work Incentive Program, omissions of minimal practical consequence to the program. ${ }^{29}$

The Quality Control regime has tended to ignore the distinction between these kinds of errors and less controversial or more serious ones. It has often fallen into a crude formalism that ignores whether the program's purposes are served by the way it designates error or by the often frenzied remedial efforts such designations induce. ${ }^{30}$

28. G. Mills, supra note 26 , at 165-70.

29. U.S. Dep't of Health, Educ. \& Welfare, Action Transmittal SSA AT-78-31 (Aug. 4, 1978); Massachusetts Dep't of Pub. Welfare, AFDC Quality Control Statistical Analysis for Review Period April 1979-September 1979 (1980) (unpublished manuscript).

Aside from serving as a means of internal identification, Social Security numbers facilitate crosschecking of welfare files and Social Security wage reports to detect unreported recipient income that can be counted against the welfare grant. However, the majority of AFDC recipients are either preschool children almost certain to be without earnings or students whose income was until 1981 exempt. If my observations in Massachusetts are typical, most of the Social Security card "errors" involve pre-school children.

The WIN program is supposed to provide job placement and training services, but it is notoriously underfunded and ineffective and has provided services to only a small fraction of registrants. Anderson, WIN: From Both Sides Now, 13 CLEARINGHOUSE REV. 584, 585 (1979). Increasing the number of registrants without increasing funding or improving administration merely adds to the number of unserved registrants and creates paper-pushing burdens for the program and the recipients.

30. For example, the reason HHS has given for counting "paper errors" in the payment error rate is that procedures such as Social Security application and WIN registration are required by statute as "conditions of eligibility." See 44 Fed. Reg. 12,581 (1979). Although the premise is correct, see 42 U.S.C. $\$ \S 602(a)(19)$, (a)(25) (1976 \& Supp. V 1981), the conclusion is a non sequitur. Legal scholarship and education have been devoted for decades to establishing that one cannot plausibly designate something a legal wrong or prescribe the consequences of such designation without reference to the purposes underlying the regulatory scheme. See, e.g., Jacob \& Youngs, Inc. v. Kent, 230 N.Y. 239, 129 N.E. 889 (1921) (failure of compliance with terms of contract not actionable if not detrimental to parties' expectations and purposes); Fuller \& Perdue, The Reliance Interest in Contract Damages, 46 YALE L.J. 52, 77 (1936) (refuting notion that any particular remedy follows from the characterization of an act as a contractual wrong).

For critical evaluations of AFDC Quality Control, see Brodkin \& Lipsky, Quality Control in $A F D C$ as an Administrative Strategy, 57 SOC. SERV. REV. 1 (1983); E. Brodkin, The Error of Their Ways: Reforming Welfare Administration Through Quality Control (unpublished M.I.T. Ph.D. dissertation 1983). My understanding of Quality Control has developed in the course of many conversations with Evelyn Brodkin and Michael Lipsky.

While legislators and the media have tended to take the public assistance Quality Control data at face value, they have shown appropriate skepticism about such data in the Social Security disability 
When different groups of decisionmakers using different procedures arrive at different conclusions in the same case, there is no occasion for surprise. When one group asserts that the other is in error, the question arises whether the assertion involves a process of measurement or a struggle for power. Whether or not AFDC Quality Control has made any contribution to the measurement of the welfare system's performance is still an open question, but it has clearly contributed to the system's transformation.

First, Quality Control has reinforced the trend toward formalization of eligibility norms. Relatively complex eligibility schemes relying on standards generate more quality control errors than relatively simple ones relying on rules. They do so, first, because they require a larger number of judgments on the part of the worker, and second, because these judgments are more susceptible to differences of interpretation between worker and reviewer. Much of the reduction in the error rate during the 1970's simply reflects the formalization discussed above. One study estimates that a third of the decline in AFDC case error rate between 1973 and 1976 (from $41 \%$ to $25 \%$ ) is attributable to formalization during that period. ${ }^{31}$ Another study advises that a state which has not yet consolidated its grants could achieve a reduction in its case error rate of 2.9 percentage points simply by doing so. ${ }^{32}$

Even when the norms are still expressed as standards susceptible to complex judgment, the review process encourages formalistic styles of interpretation. The reviewers are encouraged to adopt such styles. And where they adopt informalistic styles, they often fail to explain their judgments to the workers. Workers left without any understanding of the basis of reviewer judgment tend to adopt formalistic interpretations on the assumption that they are more likely to be correct than informalistic ones. For example, in 1979, one of the more frequently cited errors in the Massachusetts AFDC program was the failure to properly consider bank accounts in determining eligibility. Most of the errors were cited in situations in which a relative outside the home had opened and made deposits

\footnotetext{
insurance program. When Social Security Commissioner John Svahn invoked a prior finding of a 30\% "error rate" as justification for the increased rate of terminations and denials in the Reagan Administration's "accelerated" disability review program, the House Select Committee on Aging responded: "[V]irtually the entire 'error rate' is accounted for by SSA's own findings on the use of standards stricter than the law and regulations, inadequate medical documentation, and simple disagreement between two sets of adjudications examining the same evidence." HOUSE SELECT COMM. ON AGING, IMPACT OF THE ACCELERATED REVIEW PROCESS ON GESSATIONS AND DENLALS IN THE SOCIAL SECURITY DISABILITY INSURANCE PROGRAM at vi (Comm. Print 1982); see also Mashaw, How Much of What Quality?: A Comment on Conscientious Procedural Design, 65 CORNELL L. REV. 823 (1980) (benefits of accurate disability claims decisions should be weighed against costs to other values).

31. Touche, Ross \& Co., Evaluation of AFDC-QC Corrective Actions: Final Report (1977) (report to SSA) (unpublished manuscript on file with author).

32. M. BENDICK, A. LAVINE \& T. CAMPBELL, supra note 20 , at 82.
} 
into an account on which the name of one of the children in the home appeared. According to the regulation; whether such a resource is countable depends on whether it is "actually and currently available" to a member of the assistance unit. ${ }^{33}$ Although the regulations provide little further guidance, most lawyers would probably agree that deciding whether an account was "available" requires a sophisticated analysis involving banking and trust law and complicated factual judgments. Yet, the Quality Control staff apparently made their judgments summarily with minimal analysis and investigation and without communicating their interpretations to the workers. Some workers responded by counting all bank accounts. ${ }^{34}$

Second, Quality Control has intensified organizational hierarchy. It has created corps of elite officials charged with supervision of lower level decisionmaking. By prescribing detailed case reviews and using statistical techniques to generalize the results of such reviews, quality control has increased both the intensity and scope of review. The role of the relatively decentralized and collegial supervision process between worker and immediate supervisor has been correspondingly reduced. Both worker and supervisor now decide in the shadow of Quality Control, attempting to anticipate its judgments. Quality Control reviewers make judgments with little opportunity for participation by the worker or supervisor and with little or no explanation to them.

Third, Quality Control has reinforced the trend toward increased documentation requirements. The enforcement of some documentation requirements reduces error by providing more accurate information regarding substantive eligibility. However, a major portion of the documentation efforts of some states in recent years has been devoted to procedural or "paper" errors unrelated to substantive eligibility. Many administrators find increasing documentation requirements the most appealing way to reduce both paper and substantive errors because documentation requirements can be enforced by file checks, which are cheaper and require less judgment than investigations. Thus, in Massachusetts, for example, the stateinitiated quality control procedures focus primarily on documentation and rely exclusively on file checks. Reviewers make little effort to determine whether substantive errors of judgment or fact have been made; their primary task is simply to see if the correct documents are in the file..$^{35}$

The most notable instances of this tendency are consequences of HHS's

33. MASS. ADMIN. CODE tit. 106, § 304.010 (1982).

34. Interviews with Massachusetts welfare personnel (1981). The workers' response also reflects the fact that Quality Control creates incentives to resolve doubts against recipients. See infra pp. 1212-13.

35. Massachusetts Dep't of Public Welfare, Quality Assurance (1979) (unpublished manuscript on file with author). 
decision to count payments to recipients who had not secured Social Security numbers or registered for the Work Incentive (WIN) Program as erroneous. In 1979, HHS announced that Massachusetts had a $14.9 \%$ payment error rate and was faced with sanctions of nearly $\$ 5$ million for a portion of the preceding year. The announcement created a furor in the state government, and reducing error became the administration's top welfare priority. Forty-one percent of this error rate was due to Social Security and WIN "paper errors." Since these were both the largest source of errors and the most cheaply remediable, the welfare department responded with a campaign focused on them. It proceeded, not by contacting the Social Security or WIN agency to see if recipients had actually secured numbers or registered, but simply by pulling the file of every recipient and threatening to terminate those whose files lacked the official Social Security or WIN documentation unless they provided it promptly. (In many instances, the documentation was missing because the department had lost it or because the workers had assumed that they could accept less formal verification than the quality control reviewers insisted on. ${ }^{36}$ ) A major portion of the department's resources were devoted to this effort. Many recipients were inconvenienced by having to negotiate long lines at the welfare, Social Security, and WIN offices, and many who were confused or insufficiently prompt lost benefits at least temporarily. It is doubtful that these costs were offset by any substantial tangible benefit to the program. $^{37}$

Fourth, by emphasizing "positive" errors (overpayments and payments to ineligibles) and de-emphasizing "negative" errors (underpayments and wrongful denials or terminations), Quality Control may shift costs of the transformed eligibility process to recipients. The 1973 federal regulations that first linked quality control to fiscal sanctions prescribed review only for positive case actions and sanctions only for positive errors. ${ }^{38}$ The regulations were subsequently revised to prescribe review for negative actions, but negative review is more summary than positive review, and there are still no sanctions for negative errors. ${ }^{39}$ This situation creates incentives for

36. HHS had found $71 \%$ of the Social Security errors and $96 \%$ of the WIN errors to be the fault of the welfare department, rather than of recipients. Massachusetts Dep't of Pub. Welfare, supra note 29.

37. See supra note 29.

38. Improvements in Quality Control System and Reduction of Payment Error, 38 Fed. Reg. 8744 (1973).

39. See 45 C.F.R. $\$ 205.40$ (1983); Richardson, supra note 24, at 249.

Positive review routinely involves both a file check and a field investigation. Negative review relies on only a file check except in unusual circumstances. U.S. Dep't of Health, Educ. \& Welfare, supra note 29 , at 4-5.

Informally, HHS officials have often explained their refusal to sanction negative errors by asserting that the Social Security Act authorizes withholding of reimbursement to the states only for improper payments. The Act, according to this view, gives no authority to withhold reimbursement of proper 
states to behave in ways that simultaneously decrease positive errors and increase negative errors. This occurs when states resolve difficult or ambiguous issues against eligibility. It also occurs when states allocate enforcement resources toward the analysis and investigation of cases that initially appear eligible (but that upon further development may turn out to be ineligible) and away from cases that initially appear ineligible (but that on further development may turn out to be eligible). ${ }^{40}$

Perhaps the most important adverse impact on claimants arises from the fact that Quality Control does not measure failures of compliance with rules that provide important protections for claimants. These include rules that require workers to make timely responses to recipient requests for such things as grant increases, emergency benefits, replacements of lost or stolen checks, and changes of address. At the time Massachusetts undertook its major campaign to eliminate paper errors, it had recently settled a lawsuit charging it with routinely violating such rules. The consent decree enjoined the department to comply with these requirements. ${ }^{41}$ Although the department did establish some procedures in response to the decree, the paper error campaign reduced the resources available for compliance with it. Workers who previously had had insufficient time to comply with the timeliness norms now had even less time to do so because of the greater pressure to enforce documentation requirements that were measured by Quality Control. The predictable result was continued noncompliance with the timeliness norms.

While the reforms have made it more complicated for recipients to establish eligibility, Quality Control has made no effort to review compliance with the rules that entitle clients to advice and assistance in the eligibility process. It thus increases incentives to shift resources away from the provision of such assistance. ${ }^{42}$

payments on account of the improper failure to make other payments. See 42 U.S.C. $\$ \S 601,603$ (1976 \& Supp. V. 1981). The explanation seems implausible and disingenuous. The Act gives HHS general regulatory authority with specific reference to "methods of administration," id. \$ 602(a)(5), and HHS has in the past successfully taken at least as broad a view of this authority as would be required to warrant a program of sanctions for negative errors. See Burns v. Alcala, 420 U.S. 575 (1975).

40. G. Mills, supra note 26, at 100-08, 149-51, presents an elaborate statistical analysis of overpayment and underpayment data for 1975 through 1977 suggesting a "fairly severe tradeoff" between positive and negative error correction.

41. The decree and subsequent contempt proceedings are discussed in Fortin v. Commissioner of the Massachusetts Dep't of Pub. Welfare, 692 F.2d 790 (1st Cir. 1982).

42. Cf. Pesso, Local Welfare Offices: Managing the Intake Process, 26 PuB. POL'Y 305, 310, 317-21 (1978) (analysis based on two months of observations at two Massachusetts welfare offices noting low levels of information and assistance).

The importance of advice and assistance arises, not only from documentation requirements, but from the increasingly long and technical application forms. An Urban Institute study that reviewed application forms and explanatory literature, as well as data on the educational levels of AFDC recipients, concluded, "the vast majority of these documents are difficult or impossible for most of their intended audience to comprehend." M. BENDICK, A. LAVINE \& T. CAMPBELL, supra note 20, at 56. 
The Expulsion of the Social Workers, the Advent of the Clerks. The principal personnel goal of the old regime was administration at both upper and lower levels by professional social workers. The old regime emphasized three aspects of the front-line worker's job which called for the abilities of a professional social worker. First, as we have seen, financial assistance was assumed to involve relatively complex, particularized judgment. Second, financial assistance was linked to counseling, a task requiring intimate and concrete knowledge of the client and her circumstances. AFDC was originally seen as a program to enable mothers to stay home with their children, and counseling was prescribed to improve the recipient's ability as a parent and homemaker. Later, the program's purposes were reconceived, and counseling was prescribed to enhance recipients' capacities for self-support in the labor market. ${ }^{43}$ Third, an important part of the worker's job in this conception was the mobilization of community resources available outside the public assistance program to serve the particular needs of the recipient. The social worker was "among other things, a guide through a kind of civilized jungle, made up of specialized agencies and service functionaries the citizen can hardly name, let alone locate."14 At a minimum, this involved advice and referral; more ambitiously, it involved active participation in securing assistance for the client from outside agencies. The social work profession developed an elaborate body of psychosocial and pedagogical theory to educate people for these tasks.

This personnel goal was never achieved. Only a small minority of front line workers under the old regime had any social work training, and only a handful had attained the basic professional credential, the master's degree in social work. ${ }^{45}$ Nevertheless, social work professionalism had a significant influence on the sytem. From the 1930's through the 1960's, professional social workers dominated AFDG administration at the federal level and were substantially represented at higher administrative levels in

43. In 1956, 1962, and 1967, Congress expanded federal support for AFDC counseling in the hope that it would assist recipients to become self-supporting. Lurie, supra note 5, at 846-48; Rein, Social Services as a Work Strategy, 49 SOC. SERV. REV. 515, 516-19 (1975).

44. H. WILENSKY \& C. LEbEAUX, INDUSTRIAL SOGIETY AND SOCIAL WELFARE 14 (1958); see Flexner, Is Social Work a Profession?, in NATIONAL CONFERENCE OF CHARITIES AND CORRECTIONS, PROCEEDINGS 576-90 (1915).

45. In 1960 , only $1.2 \%$ of public assistance caseworkers had completed the two years of graduate training required for a M.S.W.; only $10.5 \%$ had any graduate social work education. U.S. DEP'T OF HEALTH, EDUC. \& WELfaRE, BUREAU OF FAMILY SERVICES AND GHILDREN'S BUREAU, PUblic SOCIAL WELFARE PERSONNEL-1960, at 86 (1962).

The social work model nevertheless did directly influence the practice of workers without professional training. One indication of this influence is the style of public assistance record-keeping, which involved a continuing and often astonishingly detailed description of the client and her background, together with speculations as to what kind of help would be appropriate. A good deal of Susan Sheehan's vivid portrait, S. SHEEHAN, A WELFARE MOTHER (1976), is based on the subject's AFDC case record. This style of record-keeping changed abruptly in the 1970's, when the detail and personal interest disappeared and AFDC records came to resemble business records. 
the state public assistance departments. ${ }^{46}$ During this period, the most prominent federal approach to administrative reform was to encourage professionalization of the lower level work force. Using informal pressures, regulations, and legislative proposals, federal administrators pushed for higher educational requirements for front line workers, subsidization of education at social work schools, and increases in in-service professional training for workers. ${ }^{47}$

In the 1960's and 1970's, the ideal of social work professionalism in public assistance administration was repudiated, and the actual influence of the social work profession was almost entirely eliminated. Social work lost prestige during this period as it came to be associated on the left with invasion of privacy and conformist manipulation and on the right with bleeding heart sentimentality and administrative laxity. ${ }^{48}$ Congress turned away from counseling toward economic approaches (financial incentives and work requirements) to fostering recipient self-support. ${ }^{49}$

The most important event in this development was the administrative separation of social services from financial assistance, which HHS encouraged in the late 1960's through federally sponsored demonstration projects, and mandated by regulation in $1972 .{ }^{.00}$ Proponents explained this reform as a way of reducing the danger that services would be coercively imposed on the client as a condition of financial assistance and as a way of increasing administrative efficiency through specialization. ${ }^{51} \mathrm{~A}$ consequence of this separation was that nearly all front-line workers with qualifications or aspirations as professional social workers left financial assistance to work in social services, which involved the professionally most prestigious and challenging jobs. Financial assistance jobs were then restyled as clerical. The titles "social worker" or "caseworker" were replaced with titles such as "eligibility technician" or "income maintenance worker." E2 Educational requirements were reduced and efforts were made to recruit people who did not aspire to status or responsibility beyond

46. A 1950 survey indicated that $57 \%$ of federal public assistance personnel had had two or more years of graduate social work study. M. DERTHICK, supra note 23, at 159 . A 1960 study of state personnel indicated that $9.6 \%$ of all "executives" and $15.3 \%$ of all "supervisory staff" had had two or more years and $29.3 \%$ of all "executives" and $46.6 \%$ percent of all "supervisory staff" had had some graduate social work study. U.S. DEP'T OF HEALTH, EDUC. \& WELFARE, supra note 45, at 86.

47. See M. DERTHICK, supra note 23 , at 158-89.

48. See, e.g., Glasser, Prisoners of Benevolence, in W. GaYlin, I. GLASSER, S. Marcus \& D. ROTHMAN, DOING GOOD (1978); V. BURKE \& V. BURKE, NIXON'S GOOD DEED: WELFARE REFORM 99 (1974) (Richard Nixon and Spiro Agnew on social workers).

49. See Lurie, supra note 5 , at $833-34,835-38,848-51$.

50. Separation of Services from Assistance Payments, 37 Fed. Reg. 11,060 (1972).

51. See U.S. DEP'T OF HEALTH, EDUC. \& WELFare, THE SEPARATION OF SERVICES From AssisTANCE PAYMENTS: A GUIDE FOR STATE AGENCIES 5-8 (1972).

52. See U.S. DEP'T OF HEALTH, EDUC. \& WELFARE, INCOME MAINTENANCE WORKER STUDY: A TWO-WAY TAXONOMY AND ANALYSIS III-3 to III-12 (1981). 
clerical work. As the Director of Labor Relations of the Massachusetts welfare department explained to me, "We've been trying to get the people who think like social workers out and the people who think like bank tellers in."

Parallel changes occurred at higher administrative levels. Through a series of reorganizations and cutbacks, the Nixon Administration decreased the size and authority of the HHS offices traditionally staffed by career social work professionals. At the same time, it expanded the size and authority of offices with technocratic managerial missions and staffed them with people with backgrounds in business management. ${ }^{53}$ Analogous changes in the upper tiers of state welfare administrations increased the influence of technocrats at the expense of social work professionals.

A critical result of these developments has been the expulsion from the system of people socialized to think of the frontline worker's role as involving complex, particularized judgments and direct responsibility to claimants as individuals. ${ }^{84}$ They have been replaced by people socialized to think of the role as characterized by routine, unreflective judgment and responsibility only to hierarchical organizational authority.

Division of Labor. The old regime's conception of the welfare worker's job has been decomposed into many more specialized functions- "minijobs" as one management consultant puts it.. ${ }^{55}$ The separation of social services and financial assistance is merely one example of this trend. Within financial assistance the task of taking new applications ("intake") has been separated from the task of administering established cases ("ongoing payments"). Still further divisions have been implemented or proposed: "Intake" can be divided into the function of advising the applicant of eligibility requirements and that of actual eligibility determination. The latter function may be further divided into the function of securing information regarding the claimant and that of deciding whether the information indicates the claimant is eligible. The old regime emphasized the importance of continuity of relation between worker and claimant. The new regime encourages the assignment of work so that workers have no continuing relations with claimants and claimants see a different worker every time they come in. The old regime emphasized the importance of understanding the claimant in her environmental context. The

53. Randall, Presidential Power Versus Bureaucratic Intransigence: The Infuence of the Nixon Administration on Welfare Policy, 78 AM. POL. SCI. REV. 795, 799-804 (1979).

54. Studies conducted of two midwestern welfare agencies in the 1950's indicate that a substantial portion of welfare workers did think of their job in these terms prior to separation. Blau, Orientations Toward Clients in a Public Welfare Agency, 5 AD. SCI. Q. 341 (1960); Scott, supra note 22. The latter study presents evidence that attitudes of direct responsibility to clients and to social norms, as opposed to organizational hierarchy, correlate with professional training.

55. U.S. DEP'T OF HEALTH, EDUC. \& WELFARE, supra note 52, at III-3. 
new regime is sympathetic to reforms such as Massachusetts' abolition of the system by which workers were assigned cases in accordance with the location of recipients' residences (which gave workers an opportunity to learn a neighborhood and its institutions) and began to assign cases in the alphabetical order of recipients' last names. ${ }^{56}$

The general tendency of these developments is to limit workers' understanding of the way the welfare system works and of claimants and their circumstances.

Mechanization. A variety of mechanical and computer systems have been introduced to mechanize the eligibility process. Eligibility is increasingly determined and checks are issued by computer. Welfare administrators use computers to search social insurance, employment, and bank records for evidence of unreported income and resources of recipients. The recently established Monthly Income Reporting system requires recipients to fill out and return every month an income report that a computer then uses to redetermine eligibility. Mechanization is designed to perform more efficiently operations previously done by hand and to facilitate the use of relevant but previously inaccessible information. Although some of these efforts are generally considered effective, many have been hampered by a panoply of problems attributed to inadequate design and implementation. Mass overpayments and underpayments have resulted from programming errors; poor analysis of Social Security data has triggered unwarranted fraud investigations and threats of prosecution; substantively eligible recipients have been terminated because they could not understand the monthly income report instructions. ${ }^{57}$ For our purposes, the most significant effect of mechanization has been to reinforce or facilitate some of the trends described above.

First, mechanization requires formalization. Eligibility determination can only be automated when norms are explicit and judgment, constrained. Second, mechanization facilitates centralization. A variety of functions previously performed at the local office level have been centralized through computers. Previously checks were commonly issued at the local office in emergencies. It is now relatively rare for a local office to be able to issue a check in any circumstances; the office merely generates computer input which is reviewed centrally before the check is issued by the central computer. (In Massachusetts, this change has become, if not the cause, the excuse for the system's inability to respond to emergencies.

56. See M. GREENBLATT \& S. RICHMOND, PUblic WELFARE: NOTES FROM UNDERGROUND 17 (1979) (workers' distress at alphabetization of cases in Massachusetts); S. SHEEHAN, supra note 45, at 84 (one recipient's distress at New York's change to a system in which workers have no continuing responsibility for cases).

57. See Baily, Electronic Data Processing, in CONG. Research SERV. REP. TO HOUSE COMM. ON GOV'T OPERATIONS, supra note 18, at 144-63; sources cited infra note 66. 
Whereas previously a check could be issued immediately, it now takes ten days or more.) Another example concerns work assignments for case workers. In Massachusetts, the details of work assignments were previously determined at the local office, thus making it possible for workers to participate in the decision. Assignments are now prescribed centrally and in detail for each worker by computer. Third, mechanization has encouraged intensification of the division of labor, since the machinery brings new work roles with it. Existing work must be re-divided and reapportioned among the old and new roles.

Productivity Enforcement. Quality Control has been supplemented by productivity regimes designed to measure the quantity of work and facilitate the sanctioning of low producers. Under the old regime, appraisal of productivity was relatively informal and decentralized. It was integrally related to the appraisal of quality and was largely the responsibility of the local office supervisor. The basic measure of productivity was the caseload, the number of recipients or families for whom the worker was responsible. The managers of the new regime have rejected this approach for a number of reasons. For one thing, the caseload measure depended on the system of work assignment by which workers retained responsibility for particular claimants throughout their stay in the program. This system limited the flexibility of managers in assigning work. Second, the breadth of the caseload measure limited the possibilities of hierarchical control since it did not enable the manager to monitor specific activities within the case handling job. Third, the semi-collegial nature of the supervisor worker relation was thought to inhibit the supervisor from vigorous application of coercive sanctions.

The newer productivity measurement systems are more elaborate. In 1975, for example, the business consulting firm of Coopers \& Lybrand, hired by the Massachusetts welfare department to formulate a measurement system, conducted a time-and-motion study of eligibility work. On the basis of observations of worker practices timed with stop watches, the consultants decomposed the work into more than 1000 activities and assigned to each a "reasonable" completion time based on observed averages. For example, the standards for the activities involved in redetermining eligibility include two minutes to "identify case requiring redetermination," one minute to "pull case folder," and one minute to "obtain necessary forms." These activity standards were then aggregated into various combinations to generate overall productivity standards for a wide variety of different work roles. ${ }^{58}$

58. MassachusetTs DeP'T OF Pub. Welfare, Productivity STANDaRds RePORT PRepared by COOPERS \& LYBRAND 23 (1979). 
The basic purpose of such regimes is to enhance centralization and limit worker and local office autonomy. As implemented in Massachusetts, the new system confirmed the tendency of Quality Control to allocate resources away from advice and assistance to recipients. At the time the consultants made their observations, the system was, as the department had conceded in response to a lawsuit, consistently violating the requirements regarding the timely processing of claimant requests for assistance. ${ }^{50}$ Standards that merely codified the practices (as Coopers \& Lybrand purported to have done) would have tended to perpetuate this situation. In fact, the standards implemented apparently allowed the workers even less time than before to respond to recipient requests and put greater emphasis on redetermination and policing documentation requirements. The productivity requirements contributed to the further attenuation of the worker's sense of responsibility to the client by encouraging workers to threaten clients in order to induce them to comply more promptly with documentation requirements and by implicitly penalizing time spent responding to client requests. ${ }^{\text {Bo }}$

\section{B. Effects}

The task of assessing the effects of these reforms is encumbered by a poverty of both information and concepts. Information about the effects of welfare administration tends to come in the form either of system-wide data, which tend to be limited and ambiguous, or case histories (usually from aggrieved recipients), which tend to be of questionable representativeness. There are no generally accepted standards for using the information that is available for measuring or assessing the system's performance. Nevertheless, putting aside for the moment a variety of conceptual problems and acknowledging the limitations on information, two tentative generalizations seem plausible.

First, there is no reason to believe that the administrative transformation of the system has made any major contributions either to the liberals' goal of increasing the participation rate-the percentage of the substantively eligible population that actually receives benefits-or the conservatives' goal of reducing inappropriate expenditures.

There does seem to have been a substantial increase in the participation rates in public assistance programs, and particularly AFDG, in recent decades. Much of the increase, however, seems attributable, not to administrative reform, but to the increased availability of information and advo-

59. See Fortin v. Commissioners of the Massachusetts Dep't of Pub. Welfare, 692 F.2d 790 (1st Cir. 1982).

60. Massachusetts Dep't of Pub. Welfare, The Effects of Implementing Coopers \& Lybrand's Productivity Measurement System (1977) (unpublished manuscript on file with author). 
cacy resources outside the welfare system through informal transmission, community groups, and subsidized legal services and to declining cultural inhibitions about accepting welfare. ${ }^{61}$ Administrative reform probably has made benefits more accessible in some ways, notably by reducing the capacity of the workers to deny benefits in conscious disregard of legal norms. ${ }^{62}$ But to some extent, this effect seems to have been offset by other trends that have reduced accessibility, notably by making the eligibility process more complex and burdensome and by reducing advice and assistance to applicants. ${ }^{63}$ As far as the participation rate is concerned, the reforms may simply have substituted one set of mechanisms of "disentitlement" for another. It is still the case that the system fails to deliver benefits to a substantial portion of people, including some of the most needy,

61. Statistics for New York City in the late 1950's and early 1960's indicated that the AFDC participation rate was not higher than 50\%. Cloward \& Piven, A Strategy to End Poverty, 202 NATION 510, 511 (1966). Studies in 1975 and 1976 estimated the participation rate at $87 \%$ and $74 \%$, respectively; a 1970 study put the rate for female-headed families at $90 \%$. See Bendick, Failure to Enroll in Public Assistance Programs, 25 SOC. WORK 268, 269 (1980) (summarizing studies). Rates for other programs appear to have increased as well, but generally to considerably lower levels than AFDC. Id.

The lowest participation rates reported in connection with the major public assistance programs are for those segments of Medicaid that provide partial medical reimbursement to non-welfare recipients. In the states that have this program, participation rates are estimated to run as low as 5\%. This is explained in part by the relatively small benefits due to some eligible non-recipients and in part by the extraordinary complexity of its eligibility process. See URBAN SYSTEMS RESEARCH \& ENG'G, EVALUATION OF MEDICAID SPEND-DOWN, at vii, x-xi, xvii (report to Dep't of Health, Educ. \& Welfare, Feb. 15,1976 ).

In order to consider the impact of administrative reform (formalization, bureaucratization, and proletarianization) on participation rates, one has to distinguish another phenomenon-the effect of changes in substantive eligibility norms on the amount of benefits and the number of beneficiaries. This is a difficult distinction in some instances. Many of the liberal welfare victories of the 1960's and 1970 's took the form of judicial invalidation of state regulations under federal law. From the point of view of the judiciary, one might regard this type of reform as administrative (compelling compliance with existing substantive law). But from the point of view of the lower-tier bureaucracy, this type of reform involved a change in substantive eligibility norms rather than modes of administration. The discussion in the text adopts this latter perspective.

62. While reformers are probably correct to count the decrease in conscious disregard or indifference to law as a victory for claimants, it has not been an unmixed blessing for them. On the one hand, some of the harshest anti-recipient practices documented in the welfare reform literature seem to have arisen from such disregard. Mashaw, Welfare Reform and Local Administration of Aid to Families with Dependent Children in Virginia, 57 VA. L. REV. 818, 826, 836 (1971) (denial of benefits to illegitimates; refusals to take applications from mothers before they initiate criminal support proceedings: official explains "there's the law and there's how you do things"). On the other hand, disregard sometimes benefited recipients. Advocates and workers I have talked to in California and Massachusetts say that under the old regime workers often ignored legal requirements they considered pointlessly or excessively burdensome to claimants. See M. GREENBLATT \& S. RiCHMOND, supra note 56, at 29 (Massachusetts example). In a 1967 study of the Wisconsin AFDC Program, workers reported that "they do not bother to enforce responsible relative laws, or require the disclosure of the father of an unwed mother, or apply rules about [deductions for] earned income." J. HANDLER \& E. HoL LINGSWORTH, THE "DESERVING POOR": A STUDY IN WELFARE ADMINISTRATION 199 (1971).

63. See Brodkin \& Lipsky, supra note 30; Mendeloff, Welfare Procedures and Error Rates: An Alternative Perspective, 3 PoL'y ANALYSIS 357, 362-63 (1977); M. Vesely, S. McEntree \& A. Schorr, Fair Play: A Report of a Study of the Administration of Aid to Families with Dependent Children in Several Midwestern States (unpublished manuscript, School of Applied Social Sciences, Case Western Reserve Univ., 1982). 
who meet its substantive standards of need. ${ }^{64}$

The achievements of administrative reform with respect to cost reduction also remain to be demonstrated. Payment error rates have decreased substantially, but as we have seen, reducing payment error does not necessarily lower grant expenditures (as in the case of "paper" errors), and error reduction has been achieved only at substantially increased administrative expense. Efforts to compare these added expenses with savings from error reduction have been insubstantial and inconclusive. ${ }^{65}$ And although a few specific reforms, such as some versions of periodic income reporting, appear to have reduced grant expenditures by more than their administrative costs, these savings have sometimes been achieved only by imposing large costs on eligible claimants. ${ }^{86}$

Second, the transformation of the system seems to have had an important effect on the way claimants and workers experience the system and their relation to each other. The reforms seem to have reduced the claimant's experience of oppressive and punitive moralism, of invasion of privacy, and of dependence on idiosyncratic personal favor. But they also have reduced their experience of trust and personal care and have increased their experience of bewilderment and opacity.

As far as the worker's role is concerned, the reforms have consistently reinforced experiences of alienation and subordination. Moreover, they appear to have encouraged the worker to view her own interests as in constant conflict with the claimant's. The worker's success depends on compliance with coercively enforced, intensely monitored rules that primarily require her to police the claimant's paper-pushing and bureaucratic hoop-jumping. She works in anxious awareness of pervasive but only par-

64. See Bendick, supra note 61, at 268-69; Menefee, Edwards \& Brown, Analysis of Non-Participation in the SSI Program, SOC. SECURITY BULL., June 1981, at 3, 13-20.

65. Moran, AFDC Administrative Costs, in CONG. RESEARCH SERV. REP. TO HOUSE COMM. ON GOV'T OPERATIONS, supra note 18, at 126; Richardson, supra note 24 , at 250 . A study by Touche, Ross \& Co. of 15 states with about half the AFDC caseload argues that savings from Quality Control between April 1973 and June 1976 in these states exceeded increased administrative costs by about $\mathbf{\$ 8 0}$ million, although only 9 of the states were found to have net savings. Touche, Ross \& Co., supra note 31 . This sum is substantial, though, in a program spending $\$ 7$ to 10 billion annually during this period, far from the magnitude one would expect from the more ambitious pronouncements about Quality Control. See Pratt, supra note 24, at 20. The main problem with the study is that, although it tries to remove the effects of paper errors and eligibility changes, its savings estimates take the Quality Control error measurements at face value. But for the reasons indicated supra pp. 1207-09, this is a dubious procedure. For example, Mills' more recent study argues that half the error reduction during a period that overlaps that of the Touche, Ross study is attributable, not to any change in program performance, but to reduction in Quality Control reviewer caseloads. G. Mills, supra note 26.

66. Compare B. BERNSTEIN, THE POLITICS OF WELFARE: THE NEW YORK CITY EXPERIENCE 26-30 (1982) (former New York City welfare commissioner reporting savings from city-initiated income reporting) with Center on Budget \& Policy Priorities, Research Findings on Monthly Reporting Systems and Their Implications for State Administrators (1983) (unpublished manuscript on file with author) (summarizing evidence that many federally required reporting procedures are not cost-effective and cause substantial benefit losses to eligible recipients). 
tially predictable supervisory authority in circumstances that minimize her ability to respond to the claimant's particular needs either for benefits or for assistance in the enforcement process. In this situation, the worker encounters the claimant as either a threat or a nuisance-a threat to the extent the claimant is a potential source of damaging information to supervisors monitoring the worker's performance, a nuisance to the extent that the claimant makes requests that the system disables or penalizes the worker for responding to.

\section{The Sociological Jurisprudence of Welfare Reform}

Some would argue that the defects of the new public assistance regime should be attributed, not to the general program of formalization, bureaucratization, and proletarianization, but to the specific ways the program has been implemented. Certainly, there are strong arguments for specific reforms that do not challenge the general program. For example, if the premises of the Quality Control and productivity measurement systems are to be retained, the systems should be overhauled to divert attention away from paper errors, to focus attempts to reduce improper payments on errors that are large and can be identified as errors without controversy, and to encourage compliance with rules that protect claimants, especially the rules entitling them to information and assistance and to the timely determination of claims. $^{67}$

I propose to put aside this type of analysis of specific reforms in order to focus on the general program of formalization, bureaucratization, and proletarianization. Any discussion of specific reforms necessarily takes place against a background of assumptions about the limits and possibilities of change imposed by the legal system and the society. I want to discuss the set of assumptions that has dominated writing on the welfare system during the past two decades. This dominant vision is derived from a style of sociological jurisprudence that proceeds by linking certain fundamental characteristics of modern society with a particular type of legality and in turn with a particular type of enforcement organization. ${ }^{68}$ In this manner, the dominant vision of contemporary welfare jurisprudence associates social goals such as efficiency, freedom, and fairness with a legality of formality and in turn with a bureaucratized enforcement organization staffed at the lower tier by proletarians.

67. See J. HANDLER, supra note 24, at 101-16; Mashaw, The Management Side of Due Process: Some Theoretical and Litigation Notes on the Assurance of Accuracy, Fairness, and Timeliness in the Adjudication of Welfare Claims, 59 CORNELL L. REV. 772, 810-23 (1974).

68. See R. UNGER, LAW IN MODERN SOCIETY: TOWARD A CRITICISM OF SOCIAL THEORY 23-37, 262-65 (1976). 


\section{A. Rules, Hierarchy, Proletariat}

In the early 1960's, the dominant vision was principally associated with liberals concerned with the interests of the poor; more recently it has been co-opted by conservatives concerned with cost-cutting and disciplining the public work force. ${ }^{69}$ The rhetoric of both groups has converged on the term "discretion." The dominant vision contrasts legality with discretion and prescribes the elimination or minimization of discretion. The meaning of discretion in this literature, however, turns out to be elusive. Sometimes discretion is defined simply as the absence of formalization, bureaucratization, or proletarianization. Thus, discretion can mean informality in eligibility norms (standards rather than rules), decentralized administration, or administration by professionals. Sometimes, however, discretion is defined in two more general senses.

The first sense refers to decisionmaking without regard to norms, or more simply, arbitrariness. ${ }^{70}$ Although the dominant vision frequently speaks of the problem as discretion in this sense, it seems unlikely that many of the phenomena to which it reacts are accurately characterized this way. It is extremely difficult for people to act in any setting without regard to norms, let alone in a public bureaucracy. As anthropologists have often shown in the context of primitive societies, and as Peter Blau and Michael Lipsky have shown in our context, when observers call behavior arbitrary it is usually because they either fail to perceive the norms involved or because they refuse to acknowledge them, perhaps because they conflict with the observers' own norms. ${ }^{71}$ The moralistically punitive and racist conduct in the horror stories of the old regime was wrong, but it was not arbitrary.

The second general sense of discretion is the practical ability to make a

69. The main themes of what I call the dominant vision can be found to varying degrees in nearly all the lawyers' writing on the welfare system of recent decades. The most prominent exponents of the liberal version of the dominant vision are Charles Reich, Edward Sparer, Joel Handler, Kenneth Culp Davis, and Jerry Mashaw. See, e.g., K. DAVIS, DisCRETIONARY JUSTICE (1969); Handler, Controlling Official Behavior in Welfare Administration, 54 CALIF. L. REV. 479 (1966); Mashaw, supra note 67; Reich, The New Property, 73 YALE L.J. 733 (1964); Sparer, The Role of the Welfare Client's Lawyer, 12 UCLA L. REV. 361 (1965). The most prominent exponents of the conservative version are Judge Friendly, Justice Rehnquist, and Robert Dixon. See Hansen v. Harris, 619 F.2d 942, 949-58 (2d Cir. 1980) (Friendly, J., dissenting), rev'd sub nom. Schweiker v. Hansen, 450 U.S. 785 (1981); Califano v. Boles, 443 U.S. 282 (1979) (Rehnquist, J.); R. DIXON, SOcIaL SECURITY DiSABILITY AND MASS JUSTICE (1973).

These works include some of the most creative and interesting legal scholarship of recent years, and I am indebted to them for my understanding of the welfare system. Indeed, much of my criticism simply elaborates on problems that some of these writers have acknowledged in the course of developing their own approaches.

70. K. DAVIS, supra note 69, at 4-5; J. HANDLER, supra note 24, at 5-6; Sparer, The Right to Welfare, in THE RIGHTS OF AMERICANS 65, 71 (N. Dorsen ed. 1971) (discretion as "whim").

71. P. BLAU, THE DYNAMICS OF BUREAUCRACY (rev. ed. 1963); M. LIPSKY, STREET-LeVEL BU. REAUCRACY 81-156 (1980). 
decision that violates the applicable norm. ${ }^{72}$ This is the most frequent use of the term, and much of the rhetorical power of the dominant vision derives from its tendency to associate discretion in this sense with informality, decentralization, and professionalism. Yet this general notion is often hard to apply. First, in order to identify discretion in this sense, one needs to know what the applicable norms are. But it is often, and perhaps typically, the case that there is basic disagreement over what the applicable norms are. ${ }^{73} \mathrm{~A}$ further difficulty is that, on a formal level, discretion of this sort can never be reduced. There is a law of conservation of discretion: one limits the discretion of one set of actors only by increasing that of others. ${ }^{74}$ Thus, while the dominant vision spoke generally of reducing discretion, its proposals tended to reduce only the discretion of lower level officials and to increase correspondingly the discretion of others. Conservative proposals tended to increase the discretion of upper level officials; liberal proposals tended to increase the discretion of the federal judiciary.

The rhetoric of discretion raises two related questions: the question of value and the question of trust. The question of value is how norms are to be derived to assess the conduct of public officials. The question of trust is under what circumstances officials can be relied upon to comply with applicable norms.

The dominant vision responds to these questions in terms of notions of society and law that resemble in important respects those of Max Weber. ${ }^{75}$ The starting point is a vision of dissensus and distrust as basic

72. E.g., K. DAVIS, supra note 69, at 12-14; Handler, supra note 69, at 493-95.

73. This problem does not arise where the decisionmaker acknowledges the applicable norm but refuses to follow it. See supra note 62 . But this was probably not the case in most of the situations in which the dominant vision complained of arbitrariness.

74. Here I paraphrase Kennedy \& Michelman, Are Property and Contract Efficient?, 8 HoFsTRA L. REV. 711,759 (1980).

75. 1 M. WEBER, ECONOMY AND SocietY 217-25 (G. Roth \& C. Wittich eds. 1968); 3 M. WEBER, supra, at 956-1001. Neither the rhetoric nor the ideas of the dominant vision fully coincide with Weber's sociology of law, and the primary influence on the dominant vision has been AngloAmerican liberal legalism. Nevertheless, Weber is the preemminent exponent of a critical theme of the dominant vision-the interpretation of legality in terms of both formality and hierarchical bureaucracy-that departs from the main-stream of the Anglo-American tradition. See $1 \mathrm{M}$. WEBER, supra, at 217-25; A. DICEY, THE LAW OF THE CONSTITUTION 183-205 (10th ed. 1959) (emphasizing divergence in organizational premises of Anglo-American tradition from continental legal tradition on which Weber's views focus).

Neither Weber nor contemporary welfare jurisprudence speaks explicitly of a proletarian work force. (Indeed, Weber ascribes the attributes of professional status to the bureaucratic staff, $3 \mathrm{M}$. WEBER, supra, at 958-63.) Nevertheless, I think the term proletarian best expresses the limited autonomy and judgment, limited education, and low status and reward involved in the dominant vision's conception of the welfare worker's role. For example, the use by proponents of the dominant vision of the term "quality control" for administrative review procedure analogizes welfare workers to the industrial work force. Mashaw, supra note 67, at 810-23. And proletarianization is the negative implication of the often expressed hostility for social work professionalism, which the dominant vision tends to associate with illegitimate discretion. Sparer, supra note 1 , at 733 . 
conditions of modern social life. In these circumstances, the central goals of social order are efficiency, freedom, and fairness. The goal of efficiency is to coordinate the activities of individuals so as to attain the greatest aggregate satisfaction; the goal of freedom is to enlarge each individual's autonomy to pursue her subjective goals; the goal of fairness is to protect people from the danger that collective activity will favor some citizens at the expense of others.

The Weberian view suggests that these goals are best furthered by insulating the legal system from the surrounding society and by insulating the process of enactment from the process of enforcement within the legal system. Both types of insulation are designed to minimize reliance on shared values and trust. The basic quality that insulates the legal system and the process of enactment is formality. Formality has two dimensions: one is substantive formality, which as we have seen means that law takes the form of rules with the characteristics of explicitness, constrained judgment, and impersonality. The other is procedural formality, which means that the validity of a law depends on its enactment by a specialized, unitary institution or sovereign. The Weberian view contrasts this type of legality to governance through undifferentiated or organic social norms and institutions that are informal, diffusely generated, and implicated in the conflict and dissensus of society.

The Weberian answers to the questions of value and trust are founded on this basic notion of the legal system insulated from the surrounding society by substantive and procedural formality.

The answer to the question of value is that official conduct is to be judged by the formal rules enacted by the sovereign. The basic goals of social order are thought to require this answer for several reasons. First, while organic social norms are implicated in the controversies and conflicts of the surrounding society, procedurally formal rules are generally considered fair. For reasons that vary depending on the form the sovereign takes (for example, legislature, monarch, party), it is understood (at least in the long run and relative to other social actors) to legislate in the interests of everyone. By marking off legal from other norms and establishing a link between legal norms and the sovereign, formality contributes to fairness. Second, formal rules involve consideration of fewer factors than organic social norms. This promotes efficiency because decision under rules takes less time and resources. It contributes to freedom to the extent that it limits the circumstances that trigger the sovereign's intervention in private affairs. And it is consistent with the conception of fairness that holds that the sovereign in dealing with citizens should take account of only a narrow range of broadly shared characteristics. Third, unlike organic social norms, formal rules are determinate. This is important for efficiency be- 
cause it prevents confusion, which interferes with coordination. It is important for freedom because it enhances people's capacities to plan their activities so as to best attain their goals. It is important for fairness because it enables people to perceive a basis for official decision other than personal or group preference.

The argument proceeds from this notion of formal rules as the answer to the question of value to the notion of hierarchical bureaucracy and a proletarian work force as the answer to the question of trust. This conclusion is based on both the substantive and procedural dimensions of formality. Hierarchical bureaucracy is premised on the same mechanism of control as substantive formality: rules. Moreover, substantive formality is related to the low skill and education that are defining features of proletarianism because constrained judgment tends to require less skill and education. And constrained judgment is associated with the proletarian characteristics of low status and reward: work involving constrained judgment is thought to merit low status and reward, which in turn are thought to make people more willing to have their judgment constrained.

Bureaucratic, proletarian organization is also related to procedural formality. Procedural formality expresses a commitment to order society in accordance with the will of the sovereign. Hierarchical bureaucracy with the sovereign at the top and a proletarian work force at the bottom purports to maximize the sovereign's control over enforcement.

This Weberian view of legality and organization has provoked a critique that is as well developed as the view itself. This critique surely has not been unknown to the authors of the dominant vision, but the problems the critique points to are underemphasized or obscured in their writings. The influence of the Weberian view in the dominant vision takes the form of a tendency to presume that arrangements that satisfy the conditions of formality, bureaucracy, and proletarianism are more compatible with goals of social order than those that do not satisfy these conditions. I propose here to review some of the problems emphasized in the critique and to focus on a few that seem especially pertinent to the recent history of the welfare system. The general point is not that Weberian-style legality and organization have no role to play in a plausible conception of social order, but that the presumption in its favor in the dominant vision is unjustified. Its viability depends on contingencies that the dominant vision does not directly confront.

Problems of Communication-Officials. One set of problems arises from the limitations of the means available to the sovereign for communicating norms to officials. ${ }^{76}$ From one perspective, the problems are rooted 
in the nature of the language. Language is too imprecise and indeterminate to play the role assigned to it in the Weberian view. From another perspective, the problem is rooted in the finitude of life. The sovereign does not have time to formulate precise norms for every case that may arise. Even if she did, her instructions would be so voluminous that offcials and citizens could not possibly master them. These circumstances create problems of imprecision, overload, and indeterminacy.

The problem of imprecision is that rules are over- and under-inclusive in regard to their purposes. Constraining judgment has costs in terms of the purposes of the program. The consolidation of need standards and the reduction of special and emergency benefits in the reformed system exemplifies this sort of cost. Simplified need standards pay many people more than their needs (as measured by the normative premises of the program) and many less. From the point of view of efficiency, this is a cost that must be set against gains resulting from constrained judgment.

Imprecision may also impair the goals of freedom and fairness. From the point of view of freedom, the reduction in the number of personal contingencies on which assistance is predicated has increased the claimant's autonomy of the welfare system only at the cost of exacerbating his vulnerability to the oppressions and uncertainties of private life. The recipient need submit to less inquiry about the circumstances of her life (since fewer of them are relevant), but she has less protection against many types of misfortune arising in her private affairs. The elimination in some states of replacement benefits for lost or stolen assistance checks exemplifies this disadvantage. And to the extent that fairness requires not simply treating everyone the same, but taking account of relevant differences, imprecision jeopardizes fairness. The fact that people viewed as having similar needs are treated differently (because the rules ignore some aspects of need) may fuel a sense of unfairness. ${ }^{77}$

Analysis of Legal Rulemaking, 3 J. LEGAL STUD. 257, 267-71 (1974); Kennedy, supra note 6.

77. A longstanding theme in liberal welfare jurisprudence is the appeal to the Social Security retirement program as evidence of the virtues of formality and an inspiration for the reform of public assistance. See Handler, Discretion in Social Welfare: The Uneasy Position in the Rule of Law, 92 YALE L.J. 1270 (1983); tenBroek \& Wilson, Public Assistance and Social Insurance-A Normative Evaluation, 1 UCLA L. REV. 237 (1954). I think this theme may exaggerate the degree of formality in Social Security. For one thing, the program does employ a variety of standards-type norms that require complex judgment. See, e.g., UNEMPL. INS. REP. (CCH) If 10,607 ("net earnings from selfemployment"), 12,459 ("retired"), 12,335 ("dependent" child). Even where norms are formal, they may call for complex factual judgments where they deal with circumstances not susceptible to formal proof (replacement of lost or stolen checks) or where the usual formal proof is unavailable or suspect (immigrants who lack birth certificates). And some factual determinations, notably wage history, seem simple only because the government at great expense to itself and others has kept records (and has acquired a near monopoly of relevant information) about them. More importantly, what formality there is has been achieved only at the cost of spectacular imprecision in relation to both the goal of aiding the needy and the goal of paying recipients a fair return on their contribution. See THE CRISIS IN SOCIAL SECURITY 65-86, 125-45 (M. Boskin ed. 1977). The costs of underinclusiveness in relation 
Overload is another liability of formality that has afflicted the reformed public assistance system. While the constrained judgment aspect of formality tends to simplify norms, the explicitness aspect tends to increase their volume. One of the most frequent complaints of public assistance workers these days is that they have neither the time nor sufficient memory to master the instructions the system generates so prolifically. ${ }^{78}$

While the problem of imprecision arises to the extent norms are determinate but fail to express their goals, the problem of indeterminacy arises to the extent that norms are ambiguous. It is a commonplace of contemporary jurisprudence that the most rigorously specified norms will have ambiguities that often require complex interpretive judgment and reference to social context. ${ }^{79}$ To the extent such indeterminacy exists, formality simply fails to achieve its end.

Most discussion of the problem of indeterminacy has focused on ambiguity in substantive norms. However, there is another dimension of the problem that is especially important for the dominant vision. This dimension arises from the ambiguous relation between substantive and procedural norms. Substantive legal norms are mediated by a second order of legal norms that regulates the distribution of enforcement power and resources. This second order includes rules governing waiver and default, rules that confer or deny prosecutorial authority (public prosecutorial discretion, standing, private rights of action), and rules governing the allocation of enforcement expenses and the dissemination of legal knowledge. Even given a fully determinate substantive norm, this second order of legality often makes possible controversy over whether the norm should be enforced. It is often-perhaps typically-ambiguous whether instances of non-enforcement should be understood as violations of substantive norms or vindications of procedural ones. Low participation rates in welfare programs can be viewed as a matter of violation of substantive norms. (People are not getting benefits for which they are substantively eligible.) But they can also be viewed as a matter of enforcement of procedural rules governing waiver and default. (People are not getting benefits because they have not complied with the application requirements.) More generally, the way procedural norms limit substantive norms can be understood as

to need are tolerable only because a public assistance program more sensitive to the contingencies of need exists to serve those whose needs are overlonked by Social Security. The costs of overinclusiveness in relation to need are tolerable (though this tolerance has lately been strained) only because of the largely unwarranted belief that payments represent a return on contributions. If one did not have to exclude the non-needy from public assistance, one could design an otherwise adequate program with a high degree of formality, but this does not seem a plausible condition either politically or ethically.

78. M. GREENBLATT \& S. RICHMOND, supra note 56.

79. See Fuller, Positivism and Fidelity to Law: A Reply to Professor Hart, 71 HARV. L. REV. 630, 661-69 (1958). 
accommodating a variety of social goals not adequately specified in the substantive law. Thus, to some, low participation rates, even when they result from burdensome application procedures, indicate, not the failure of social order, but its vindication; they simply show that the system has worked to ration scarce public resources and serve the goal of fiscal economy. ${ }^{80}$

The Weberian view seems unable to come to terms plausibly with such views or the experiences from which they arise. It tends to conflate legality with substantive law and to see all substantive enforcement as a vindication of order. ${ }^{81}$ But this is implausible. First, it simply ignores the extent to which law enforcement is experienced in the society as disorder. For example, an interesting development of the past two decades has been the emergence of a radical literature calling for law enforcement as a means of disrupting and weakening the established order. Some radical theorists embraced the liberal Weberian program of welfare enforcement in the hope of hastening the fiscal collapse of the state and the consequent egalitarian transformation of the society. ${ }^{82}$ And in fact, the increased participation rates induced by the enforcement efforts of the 1960's did generate a sense of crisis consistent with some of the more modest of these predictions. A sociology of law incapable of distinguishing between what people experience as normal social practice and what they experience as crisis does not seem very satisfactory. Second, conflating substantive norm enforcement with order is inconsistent with the most plausible approach to substantive interpretation. The sovereign legislates particular substantive rules against a background of second order procedural rules and social practices that generally limit enforcement. Though it is rarely clear what impact the sovereign intended this regime to have on the enforcement of a particular rule, it usually seems likely that it did intend the regime to have some limiting impact. Third, almost all the Weberians acknowledge some areas of law in which limited enforcement is compatible with social order. For example, liberals generally approve of limited enforcement of the soft drug and prostitution laws; conservatives, of the desegregation and criminal defendants' rights laws. Yet nothing in the basic Weberian premises suggests any basis for such distinctions. ${ }^{83}$

The enforcement dimension of indeterminacy creates basic problems for the dominant vision. This vision answers the question of value by appealing to the substantive law as an uncontroversial basis for criticizing the

80. See H.R. Rep. No. 97-139, 97th Cong., 1st Sess., reprinted in 1981 U.S. CODE CoNG. \& AD. NEwS 454-55 (explaining elimination of requirement of Food Stamp statute that administering agencies engage in "outreach" activities).

81. See Abel, Law Books and Books About Law, 26 STAN. L. REV. 175, 184-89 (1973).

82. A. WOLFE, THE Limits OF LEGiTiMACY (1979); Cloward \& Piven, supra note 61.

83. I consider efforts to modify the Weberian view to permit such distinctions infra pp. 1250-69. 
performance of public officials. But the problem of indeterminacy indicates that to criticize officials for not enforcing the substantive law either assumes a mistaken notion of social order (order equals substantive enforcement) or is question-begging (it fails to explain why particular rules should be enforced and others not). Moreover, the problem of indeterminacy undermines the Weberian answer to the question of trust in terms of bureaucratic control. If the Weberian denies that officials exercise discretion or judgment to resolve indeterminacies of enforcement, then he cannot explain how these indeterminacies are resolved; on the other hand, if he recognizes that officials exercise such discretion or judgment, he cannot explain why they can be trusted to do so. When the Weberians do recognize that officials exercise enforcement discretion, they can only deplore this fact and urge more formalization of procedural norms governing enforcement. ${ }^{84}$ But, of course, this response exacerbates the problems of imprecision and normative overload.

Problems of Communication-Citizens. The problems of imprecision, overload, and indeterminacy limit even more severely the sovereign's capacity to communicate to citizens about their rights, since the citizens tend to have less ability to master the law than the officials.

As the enforcement process has become increasingly complicated in the reformed welfare system, the citizen has become increasingly dependent on legal knowledge. Most obviously, she needs to know what benefits there are in order to apply for them. She also needs to know what information she must provide in order to establish eligibility. Often, the relevant facts will be ambiguous, and her eligibility will depend on how she characterizes them. ${ }^{85} \mathrm{Her}$ eligibility may depend also on how she structures her private affairs prior to application..$^{86}$ She also needs to know what procedural steps she must take, for example, what documents she must procure. She cannot fulfill a requirement even as simple as a written application unless she knows of the requirement, knows how to secure an application, and knows how to fill it out. ${ }^{87}$

84. See K. DAVIS, supra note 69; Handler, supra note 69.

85. For example, whether a migrant worker will be found to satisfy the residence requirement for AFDC, 45 C.F.R. $\$ 233.40$ (1983), will depend on whether she is able to give the correct responses to often highly ambiguous questions concerning her travel and work plans.

86. For example, in some AFDC programs, whether a recipient who shares an apartment or who borrows money suffers a grant reduction depends on whether the rental or loan agreement satisfies specified formal conditions. E.g., MASS. ADMIN. CODE tit. 106, § 304.510 (1982) (rent regulation); CALIFORNIA DEP'T OF SOCIAL SERVICES, MANUAL OF POLICIES AND PROCEDURES \$ 44-111.437 (loan regulation).

87. See, e.g., Schweiker v. Hansen, 450 U.S. 785 (1980) (government not estopped to deny retroactive Social Security benefits to woman who was discouraged from filing an application by worker who wrongly told her she was ineligible); M. BENDICK, A. LAVINE \& T. CAMPBELL, supra note 20, at 56 (" $[\mathrm{T}]$ he vast majority of [applications and other documents provided claimants] are difficult or impossible for most of their intended audience to comprehend."). 
The citizen's dependence on such knowledge raises doubts about the capacity of the system to secure the goals of freedom and fairness. The system is supposed to safeguard the citizen's autonomy and insure evenhanded treatment by binding officials to the rules. But even in a system of perfectly enforced rules, the officials will have power over the citizens and over the incidence of enforcement to the extent they have control over the distribution of enforcement resources such as information and assistance. While the public assistance reforms of recent decades have sought with some success to limit the kind of discretion that arises from informal norms and limited supervision, they have enlarged the kind of discretion that arises from the control of enforcement resources. Claimants' dependence on enforcement resources has grown with increased procedural requirements.

I suspect that many liberal lawyers underestimate this point because of their vocational perspective. The transformation of the system has increased its accessibility and responsiveness to people with rule knowledge and enforcement resources, in particular professional advocates. But very few recipients have the knowledge and resources of professional advocates and only a few more are able to get representation by professional advocates. $^{88}$ For the rest, formalization and bureaucratization have in many ways decreased accessibility and responsiveness.

Now it might be thought that this objection does not go to the Weberian project itself, but to the perverse implementation of it in the recent reforms. The reforms have notably failed to formalize and bureaucratize many of the critical aspects of the provision of enforcement resources. Thus, there are responses within the dominant vision to the failure of the current regime to secure information and assistance. Such responses would require workers to provide specified packages of enforcement resources that would differ from applicant to applicant only in terms of a small number of characteristics. The Miranda warnings given by policemen to those they arrest exemplify this kind of activity.

But such responses are plagued by imprecision, overload, and indeterminacy. In order to serve the goal of freedom, the enforcement activities must achieve a genuine understanding by the right-holder of her rights and what she has to do to enforce them and must provide her with the assistance she needs to do so. But the process of informing lay people about legal rights is complex and difficult. This is particularly so when it involves people who are relatively uneducated and with limited experience of the dominant culture, as both criminal defendants and welfare recipi-

88. Even among the small fraction of AFDC applicants and recipients who took appeals to administrative hearings, see infra note 124 , only $11.5 \%$ had any kind of representation in fiscal 1980. U.S. DEP'T OF HEALTH \& HUMAN SERVS., Q. PUB. ASSISTANCE STATISTICS, Jan.-Mar. 1981, at 25. 
ents tend to be. As students of the Miranda warning have concluded, a plausible attempt to impart understanding to such right-holders must involve sensitivity on the part of the person providing the information to personal and social characteristics of the particular right-holder and an ability to shape communication and assistance in accordance with these characteristics. ${ }^{89}$ Such an approach would seem to require informal, particularized judgment, lower-level autonomy, and sophistication and training to a degree incompatible with the dominant vision. ${ }^{90}$

Problems of Supervision. The Weberian view relies on each successive layer of administrative hierarchy, culminating in the sovereign, to superin-

89. Griffiths \& Ayres, A Postscript to the Miranda Project: Interrogation of Draft Protesters, 77 YALE L.J. 300, 318-19 (1967); Note, Interrogations in New Haven: The Impact of Miranda, 76 YALE L.J. 1519, 1577-78, 1613-16 (1967).

Bendick concludes on the basis of studies of welfare "outreach" efforts that, "Because of the ineffectiveness of mass-media outreach campaigns, face-to-face interaction, patient communication with the client in his or her own terms, and follow-up assistance in the application process may be necessary elements of outreach for the recruitment of most needy nonparticipants." Bendick, supra note 61, at 271.

90. The problem of communication about rights and provision of enforcement resources exemplifies a basic dilemma of the dominant vision and of liberal legalism generally. It is a premise of liberal legalism that legally competent citizens must have the ability to know their rights and duties and to enforce and perform them. This imposes an obligation on the state to make the law known to citizens and to make performance and enforcement possible. Société Internationale pour Participations Industrielles et Commercials, S.A. v. Rogers, 357 U.S. 197 (1958); Lambert v. California, 355 U.S. 225 (1957); see L. FULLER, THE MORALITY OF LAW 49-51, 63-65, 70-79 (rev. ed. 1969). The problem is that liberal legalism does not have a satisfactory answer to the question of whether the state's obligations are measured by a subjective standard, which would require that each citizen be guaranteed an opportunity to know and enforce her rights, or an objective standard, which would require some uniform standard regardless of the capacities and circumstances of individual citizens. A subjective standard would undermine formality and bureaucracy by making enforcement depend on a multitude of personal characteristics of each right-holder. But an objective standard deprives a broad segment of the citizenry of the freedom promised by legality and makes enforcement turn on substantively irrelevant factors such as wealth and education. Compare Goldberg v. Kelly, 397 U.S. 254, 268-69 (1970) ("The opportunity to be heard must be tailored to the capacities and circumstances of those who are to be heard.") with Guerrero v. Carleson, 9 Cal. 3d 808, 512 P.2d 833, 109 Cal. Rptr. 201 (1973) (notice required by due process need not be in language understandable by non-English speaking claimant), cert. denied, 414 U.S. 1137 (1974).

These issues are rarely faced in the welfare area. With a few exceptions, welfare statutes do not attempt to require the provision of enforcement resources. See Note, Outreach: Bringing the Eligible into Federal Assistance Programs, 62 CORNELL L. REV. 1093 (1977). Judicially developed doctrine is sparse, vague, and inconsistent. On the one hand, it is often said that the burden of proof with respect to eligibility is on the claimant. Lavine v. Milne, 424 U.S. 577 (1976); Torres v. Schweiker, 682 F.2d 109 (3d Gir. 1982), cert. denied, 103 S. Ct. 823 (1983). And in a case holding the government not estopped to deny benefits to a woman who had failed to file an application because a Social Security worker erroneously told her she was ineligible, the Supreme Court apparently assumed that neither due process nor the substantive statute implicitly create a duty to provide information and facilitate application. Schweiker v. Hansen, 450 U.S. 785, 789-90 (1981). On the other hand, some cases explicitly or implicitly recognize the limited ability of claimants to secure evidence and shift the burden of proof to the government. See Krauss v. A. \& M. Karagheusian, Inc., 13 N.J. 447, 456-57, 100 A.2d 277, 282 (1953) (Brennan, J.); Liebman, The Definition of Disability in Social Security and Supplemental Security Income: Drawing the Bounds of Social Welfare Estates, 89 HARV. L. REV. 833, 850-51 (1976). Still others recognize governmental duties to provide information and assistance to claimants, whether by virtue of due process, common law estoppel, or inferences from substantive statutes. See Jagow v. Child, 95 Idaho 830, 521 P.2d 654 (1974). Some use language suggesting a subjective standard. See Crowder v. Gardner, 249 F. Supp. 678, 680 (D.S.C. 1966). 
tend the activities of the layers below it. A critical problem with this approach is that each level of the hierarchy receives a progressively narrower range of information regarding matters within the control of its subordinates. In important respects, the supervisors have less information than those they supervise. Thus, the sovereign and her supervisors may lack sufficient information to formulate enforcement norms or to detect willful non-compliance with the norms. Supervision may cause subordinates to focus their efforts on the activities most easily reviewed by supervisors even though such a focus may be inconsistent with the substantive goals of the program. In a famous illustration of this point, Peter Blau showed how the introduction of productivity standards based on the number of job referrals for officials in a public employment service caused the officials to devote their efforts to the most easily employable applicants, many of whom would have found jobs without their help, and to ignore more difficult cases that could have benefited more from help. ${ }^{91}$ As we have seen, this pathology pervades the AFDC Quality Control system.

Problems of Alienation. A further set of concerns arises from the failure of the Weberian view to address the phenomenon of alienation.

One widely recognized problem is that the tendency of formality and bureaucracy to alienate the worker from the goals of the enterprise may jeopardize efficiency. ${ }^{92}$ Workers who share the goals of the enterprise will contribute their efforts and comply with its norms voluntarily. Because the ability to induce effort and compliance through hierarchical supervision is limited by the problems of supervision, voluntary contribution and compliance enhance efficiency. Organizations modeled on the Weberian view thus may undermine efficiency by virtue of their impact on the workers' goals. Widespread impressions of high turnover and low morale in the public assistance system suggest this problem may be present there.

A more elusive but perhaps more important problem is that the tendency of the system to alienate the citizen undermines the goal of freedom. The Weberian view purports to secure freedom simply by insuring that the citizen is subject only to formally and bureaucratically constrained power. This view does not require that the system guarantee the ability to satisfy any particular goal or need or that it take into account any particular characteristic of the citizen. In contrast, an important tradition of criticism asserts that a plausible notion of freedom must make provision for some recognition of the concrete individuality of the person. ${ }^{93}$ It suggests

91. P. BLAU, supra note 71 , at $36-56$.

92. E.g., M. CROZIER, THE BUREAUCRATIC PHENOMENON 187-98 (1964); A. GOUldNer, PatTERNS OF INDUSTRIAL, BUREAUCRACY 207-14 (1954).

93. G. HEGEL, PHILOSOPHY OF RIGHT 75-104 (T. Knox trans. 1953). Weber himself contributed to this tradition. M. WEBER, Science as a Vocation, in FrOM MAX WEBER: ESSAYS IN SOcIOLOGY $129,155-56$ (1946). 
that formalized, bureaucratized power may be perceived as arbitrariness or oppression. Whether in fact such power is perceived as freedom or as arbitrariness or oppression seems to vary with social and personal circumstances in ways that the dominant vision does not acknowledge. For example, some of the long-term welfare recipients I met in Boston expressed nostalgia for the old, unreformed system as one that "cared more" about them. They missed the special needs grants. Although I doubt that their total grants were larger before consolidation, they interpreted the particularized need standard as an expression of concern about them as individuals. They also missed the long-term relation with an individual worker. They missed the workers' expressions of interest in their lives. And they missed the sense that the office they dealt with was rooted in the community. ${ }^{94}$ It would have been totally meaningless to them to suggest that this loss had been compensated by an enlargement of their freedom. Such feelings were not universal and perhaps not even typical. But a conception of freedom indifferent to such feelings seems inadequate.

Even if we ignore such feelings, the plausibility of the conception of freedom as subjection to formalized, bureaucratized power still depends on the assumption that the citizen exercises autonomous choice within the framework of such power. I mentioned above that the problems of communication cast doubt on this assumption. The doubt is intensified by the problems of alienation, since they suggest that the citizen's perception of her goals may be influenced by the legal system. Consider a recent study of the effects of the administrative separation of financial assistance and social services. One of the main arguments for this reform asserted that it would enhance the client's capacity for choice by limiting the ability of workers to force services on the client by tacitly conditioning financial assistance on acceptance of services. ${ }^{95}$ The study suggests how problematical the notion of choice in this argument is. It reports on differences in requests for both financial assistance and social services by clients with similar information and background characteristics in different administrative settings and concludes that separation reduces requests, not only for social services, but for financial benefits as well. The authors speculate that in the combined function model the interest expressed by workers in the recipients' personal circumstances relaxes their shame-induced inhibitions

94. There are similar expressions of nostalgia in S. SHEEHAN, supra note 45 , at 18-31, 83-85. Joel Handler's and Ellen Jane Hollingsworth's 1967 study of the Wisconsin AFDC program found a high level of recipient satisfaction in the personal aspects of the caseworker relation, although these aspects were more limited than the social work doctrine of the old regime prescribed. J. HANDLER \& E. HOLLINGSWORTH, supra note 62, at 103-63.

95. U.S. DEP'T OF HEALTH, EDUC. \& WELFARE, supra note 51, at 5-6; J. HANDLER \& E. HOL LINGSWORTH, supra note 62 , at $130-33$. 
about requesting financial assistance. ${ }^{96}$ Whether or not this interpretation is correct, the study suggests that what people express as their goals is influenced by the organizational structure in which they express them. This suggestion undermines the claim of the Weberian regime to enhance freedom. In order to decide which of the different patterns of choices associated with different administrative arrangements more accurately represents the claimant's goals, one would need a conception of individual goals that did not depend on the claimant's choices. One would need a nonsubjective conception of needs or interests. But the Weberian view has no such conception.

The Organizational Paradox of Formality. A final problem with the Weberian view overlaps some of the problems of communication, supervision, and alienation. It arises from the indeterminate and paradoxical relation of substantive and procedural formality. It suggests that the Weberian answer to the question of trust (hierarchical bureaucracy) not only does not follow from the Weberian answer to the question of value (formal rules), but may not even be compatible with it.

Substantive formality requires that the sovereign's will be expressed as rules. This principle seems to preclude direct participation of the sovereign in enforcement because such participation leads to ad hoc decision based on unformulated criteria. Hence the notion that enforcers should be independent of the sovereign. On the other hand, procedural formality requires that enforcement comply with the will of the sovereign. This principle seems to require direct participation of the sovereign in enforcement because the problems of communication prevent rules from fully expressing the sovereign will. Hence the notion that enforcers should be subject to the control of the sovereign ${ }^{97}$ These conflicting implications exemplify

96. Piliavin \& Gross, The Effects of Separation of Services and Income Maintenance on AFDC Recipients, 51 SOC. SERV. REV. 389, 403-04 (1977).

97. The fact that it is often difficult to identify a unitary sovereign in American legal culture is another difficulty with the Weberian view. Public law discourse influenced by the Weberian view usually presumes that the legislature is the relevant sovereign, that top level executive officials are closest (most directly accountable) to it, and that lower level officials become accountable to the legislature as they become subordinate to upper level ones. See V. OSTROM, THE INTELLECTUAL CRISIS IN AMERICAN PUBLIC ADMINISTRATION 23-47 (1973); Wilson, The Study of Administration, 2 POL. SCI. Q. 197 (1887). But this perspective often encounters difficulties from two traditions. First, the constitutionalist tradition holds that the sovereign people have divided power among the three branches and limited the power of each. In this view, it is sometimes hard to determine which branch has preeminence and to what extent the constitutional limitations on each of them can be enforced by lower level executive authority or citizen self-help. See M. KADISH \& S. KADISH, DISCRETION TO DISOBEY 37-140 (1973). Second, the pluralist tradition holds that sovereignty should be and has been divided up by myriad private groups. In matters within the sphere of their interests, compliance is owed to the wills of such groups. See Stewart, The Reformation of American Administrative Law, 88 HARV. L. REV. 1667, 1760-90 (1975); Yeazell, Intervention and the Idea of Litigation: A Commentary on the Los Angeles School Case, 25 UCLA L. REV. 244 (1977). To the extent that legal doctrine portrays sovereignty as diffused in either way, it further undercuts the Weberian association of procedural formality and bureaucratic hierarchy. 
a general instability in the liberal understanding of legality, which sees law as a means of both restraining the sovereign and extending its power.

For our purposes, the important aspect of the problem is that substantive formality contradicts the hierarchical implications of procedural formality. Procedural formality purports to limit discretion through hierarchical organization; it thus makes it possible for superior officials to argue that their organizational proximity to the sovereign gives their views authority. But substantive formality purports to limit discretion through the rules themselves; it thus makes it possible for subordinate officials to appeal beyond their superiors to the rules.

This possibility has been illustrated throughout modern history by the various struggles of judicial officers for autonomy from executive authority in particular and hierarchical authority in general. It is expressed in the principle of some European constitutions that "[j]udges are subject only to the law"98 and in the civil law doctrine that a lower court judge is not bound (at least on first remand) by a judgment of reversal by an appellate court. ${ }^{99}$ It is also expressed in the American doctrine of judicial review that permits lower court judges to enjoin the actions of the highest executive officials. ("A court that checks Uncle Sam's agents is not limiting Uncle Sam's will but is helping to carry out his will," Kenneth Culp Davis writes. $)^{100}$ And it is expressed in principles that recognize the right of citizens to appeal directly to the law over the heads of officials, for example, in the doctrines that allow juries to reject judicial instructions at trial and citizens to reject executive prohibitions regarding their conduct in the hope of subsequently establishing its legality in court. ${ }^{101}$ Such doctrines are based on the belief, inspired by formalistic conceptions of legality, that people have an unmediated relation with the law itself. The defiant subordinate can claim the support of the sovereign by arguing that the sovereign's will is embodied in the rule (as she interprets it) and not in the superior's command. ${ }^{102}$

The Weberian perspective ignores the organizational paradox of for-

98. See Const. of Italy, art. 101, โ 2; M. CAPPELletTI \& W. COHEN, COMParative ConstituTIONAL LAW 330-57 (1979).

99. J. DAWSON, THE ORACLES OF THE LAW 403-05 (1968).

100. K. DAVIS, supra note 69, at 175.

101. See M. KADISH \& S. KADISH, supra note 97 , at 37-94.

102. See L. WHITE, THE FEDERALISTS 204 (1948):

The extent of the Secretary of the Treasury's power of superintendence was challenged by some customs collectors, who alleged that their oath of office required them to execute their offices according to the law, and thus allowed them to follow the law as they understood it, not as it might be explained to them by Alexander Hamilton.

A more recent example is the refusal of some state welfare officials responsible for Social Security disability determinations to follow instructions from the Reagan Administration designed to limit favorable determinations on the ground that the instructions violate the Social Security Act. Lauter, Disability-Benefit Cases Flood Courts, Nat'l L.J., Oct. 17, 1983, at 1. 
mality: It tends simultaneously to encourage the constitution of hierarchical enforcement authority and to encourage individuals to appeal beyond constituted authority to the sovereign will itself. To the extent that such appeals occur, they are often perceived as disorder. ${ }^{103}$ To the extent they are inhibited by procedural norms, substantive norms often inspire a sense of oppression or unfairness. ${ }^{104}$ The paradox means that the organizational implications of formality are more indeterminate than the Weberian view allows. There is no basis from which to presume that hierarchical bureaucracy maximizes compliance with the sovereign will or serves the goals of social order. In fact, most modern legal and administrative systems are a hodgepodge of centralization and decentralization, and even in the ones most committed to the Weberian view the paradox asserts itself in anomalous norms such as the civil law rule about the freedom of the trial judge on remand or the contemporary American concern with "whistle blowing" by subordinate executive officials. ${ }^{105}$

Two California cases are examples of such anomalies in the context of recent welfare reforms. In one, the California Supreme Court held that a welfare worker could not be discharged for disobeying her supervisor's order to engage in a search of a recipient's home that the worker asserted (and the court agreed) was unlawful. ${ }^{106}$ In another, it held that a welfare appeals official has the authority and duty to ignore a welfare department regulation when she decides it is in conflict with a statute. ${ }^{107}$ Neither decision has had a dramatic impact, and it is easy to formulate limiting interpretations of each. (The first decision concerns physical conduct rather than decisionmaking; the second concerns quasi-judicial officials rather

103. For example, see Dawson's discussion of the degeneration of nineteenth century French legal scholarship into a "chaos of clear ideas":

It is strange and paradoxical that the supremacy attributed to the legislature should have maximized this individual self-assertion. Yet one can follow the reasoning that greatly influenced attitudes .... . If the interpreter was to be faithful to his high mission he must fix his eyes on the authentic text and penetrate through the encasing words to the living thought of the legislature. He could take aid from others but the task was essentially for him alone.

J. DAwSON, supra note 99 , at 395-96.

The organizational paradox of formality parallels a central paradox of Protestant theology. See D. LITTLE, RELIGION, LAW AND ORDER: A STUDY OF ELIZABETHAN ENGLAND 38-56 (1969).

104. See Walker v. City of Birmingham, 388 U.S. 307, 324 (1967) (Warren, C.J., dissenting) (criticizing majority's decision that Martin Luther King and others could be punished for violating unconstitutional injunction as oppressive and likely to undermine confidence in legal system).

105. See Damaska, Structures of Authority and Comparative Criminal Procedure, 84 YALE L.J. 480, 494-98 (1975); Vaughn, Statutory Protection of Whistle Blowers in the Federal Executive Branch, 1982 U. ILL. L. REV. 615.

106. Parrish v. Civil Serv. Comm'n, 66 Cal. 2d 260, 425 P.2d 223, 57 Cal. Rptr. 623 (1967).

107. See Woods v. Superior Court, 28 Cal. 3d 668, 680, 620 P.2d 1032, 1038-39, 170 Cal. Rptr. 484,490 (1981). The counter-hierarchical implications of the decision are limited by the fact that the California appeals system permits the welfare department director to review the appeals official's decision before it becomes effective. CALIFORNIA DEP'T OF SOCIAL SERVS., STATE DEPARTMENT OF SOCIAL SERVICE MANUAL § 22-061. 
than bottom tier administrators.) But the cases do not mention such interpretations; they rely on a premise with broadly counter-hierarchical implications: that invalid orders or regulations "have no force or life."108

The most notable expression of the decentralizing implications of substantive formality in welfare in recent years was the welfare rights movement. Even in some of its most defiant moments, the movement was animated by (usually very plausible) appeals to substantive legal rights. Some of its most successful efforts involved pressure by groups of recipients (often through threats of violence) on local offices to enforce rights to special need grants. There is some irony in the fact that the elimination of special need grants and of local office autonomy-reforms promoted by liberal lawyers in the name of recipient rights ${ }^{\mathbf{1 0}}$ - played an important role in killing this particular form of quality control.

A Further Illustration. The range of problems of the dominant vision is apparent in the current efforts of the Reagan Administration to come to terms with the widely varying but generally high reversal rates in disability appeals to Administrative Law Judges (ALJs) of the Social Security Administration. For many years, reversal rates have averaged around fifty percent or more, but they have varied widely among individual ALJs; some judges decide for claimants in a high percentage of cases; other judges applying the same substantive norms decide for claimants in a low percentage of cases. How does one decide whether either or both groups are performing improperly? The Reagan Administration responded to this challenge by having the Social Security Administration's Appeals Council review the files of a sample of cases decided by ALJs. The Reagan Administration reasoned that since by law the Appeals Council has the highest authority within HHS with respect to disability decisions, its decisions on review are presumptively correct. Because the Appeals Council disagreed with the ALJs' reversals more frequently than with their affirmances and with the high reversal rate ALJs more frequently than the low reversal rate ALJs, the Administration interprets the study to show that the ALJs are reversing too much. It has used the study to justify a series of reforms designed to decrease reversals, including instructing the

108. Woods, 28 Cal. 3d at 680, 620 P.2d at 1038-39, 170 Cal. Rptr. at 490 .

109. See J. HANDLER \& E. HOLLINGSWORTH, supra note 62 , at 198-99, 208-11. When welfare departments initiated consolidation in response to the welfare rights movement, the reform was perceived as conservative and opposed by liberal advocates. The irony is that the liberals were answered with the Weberian arguments they themselves had developed. See L. BAILIS, BREAD OR JUSTICE 143 (1974).

The opposition to consolidation in the course of the welfare rights movement is one of numerous instances in which liberal advocates took positions inconsistent with the dominant vision. However, these positions were ad hoc and were never integrated into an alternative perspective to the Weberian view. That view did not inform every position the advocates took, but it was the dominant theoretical influence on their work. 
ALJs to follow the voluminous and relatively formal rules of the Program Operating Manual System designed for front-line workers and focusing supervisory efforts on the high reversal rate ALJs. ${ }^{110}$

This program exemplifies the problems of the Weberian view. First, there are problems of communication, particularly imprecision. As the Administration admits, the Program Operating Manual System's instructions are substantially under-inclusive. ${ }^{111}$ They deny eligibility to a large number of applicants with disabilities, such as psychiatric ailments or ailments that cause disabling pain, which cannot be established with simple physical observations or quantitative medical tests. They do this despite the fact that nearly everyone permitted to make a judgment on the matter believes that many of these claims are within the substantive legislative norm. ${ }^{112}$

Second, there are problems of supervision. Because the Appeals Council's review was conducted on a paper record, it lacked some information available to the ALJs who made the decisions under review: physical appearance and demeanor of the claimant. American law has always asserted the importance of this type of information in doctrines such as those limiting the scope of appellate review of trial court findings of fact and the right of confrontation. Appearance and demeanor are often dispositive in two of the largest categories of cases that come to the ALJs: cases involving psychiatric impairments and those turning on assessments of the degree of pain.

Third, there are problems of alienation. By reducing the capacity of the ALJ to respond to the contingencies of the particular case, the reforms reduce the capacity of the system to treat the claimant as a concrete individual. From the claimant's point of view, the reforms would make the appeal less an inquiry about whether he can legitimately be expected to earn his own living and more an inquiry about whether he fits a set of formal categories that have no perceptible relation to his experience and needs. ${ }^{113}$

And fourth, there is the organizational paradox of formality. The same factors that make the Administration doubt the authority of the $\mathrm{ALJs}$ - their administrative insulation from the immediate control of the

110. The Bellmon Report, supra note 15, at 3; SUBCOMM. ON OVERSIGHT OF GOVERNMENT MANAGEMENT, SEN. COMM. ON GOVERNMENTAL AFFAIRS, THE ROLE OF THE ADMINISTRATIVE LAW Judge in the Disability adjudication Process 22-24 (Comm. Print 1983).

111. The Bellmon Report, supra note 15, at 12-15.

112. See Bittel v. Richardson, 441 F.2d 1193 (3d Cir. 1971); Miracle v. Celebrezze, 351 F.2d 361 (6th Cir. 1965).

113. See Mashaw, The Supreme Court's Due Process Calculus for Administrative Adjudication in Mathews v. Eldridge: Three Factors in Search of a Theory of Value, 44 U. CHI. L. REV. 28, 49-52 (1976). 
sovereign and their ethos of decisional independence-from another point of view inspire confidence in them. And the same factor that gives the Administration confidence in the authority of the Appeals Council-its proximity to the sovereign-raises questions about it. The Appeals Council's lesser independence and its closer association to policymaking executives associated with the Reagan Administration's budget cutting commitments undermines the claim to authority from its superior position in the hierarchy. These factors suggest that the review judgments may represent, not more accurate applications of the disability norms, but the betrayal of those norms to the Reagan Administration's ad hoc policy commitments. ${ }^{114}$

\section{B. Standards, Decentralization, Profession}

If the Weberian view were considered as one end of a spectrum of sociologies of law, the view at the opposite end would characterize society as founded on shared values and trust, and law as largely undifferentiated from organic social norms. There would be no distinction between enactment and enforcement; both sovereignty and enforcement powers would be diffused throughout the society and would involve extensive self-help, unspecialized decentralized institutions, and broad participation. Although this view is most readily associated with traditional societies, it bears some resemblance to the accounts of revolutionary America by recent historians and of early nineteenth century America by Alexis de Tocqueville. ${ }^{115}$

But of course the view of legality and society that competes in contemporary America with what I have called the dominant vision in welfare jurisprudence is not this vision of undifferentiated legality. The competing view aspires to synthesize the two polar views. This competing view resembles the program of the social work profession under the old regime of welfare administration, but in recent decades its most prominent influence has been in the literature on the judiciary. The competing view has been developed in theories of reasoned elaboration and irrebuttable presumptions, of due process and process values, of judicial administration, and of federal habeas corpus, class actions, and structural remedies. ${ }^{116}$

114. See HEW Efforts, supra note 24.

115. A. DE TOCQUEVILLE, DEMOCRACY IN AMERIGA 213-26, 241-90 (J. Mayer \& M. Lerner eds. 1966) (emphasis on enforcement through diffuse social pressures and the jury); G. WOOD, THE CREATION OF THE AMERICAN REPUBLIC, 1776-1783 at 319-28 (1969) (emphasis on self-help and enforcement through "The People Out-of-Doors"); Nader, Styles of Court Procedures: To Make the Balance, in LAW IN CULTURE AND SOCIETY 69 (L. Nader ed. 1969).

116. See J. DAwSON, supra note 99; P. FISH, THE POLITICS OF FEDERAL JUdicial ADMinistraTION (1973); Chayes, The Role of the Judge in Public Law Litigation, 89 HARV. L. REV. 1281 (1976); Fiss, The Supreme Court, 1978 Term-Foreword: The Forms of Justioe, 93 HARV. L. REV. 1 (1979); Neuborne, The Myth of Parity, 90 HaRV. L. REV. 1105 (1977); Tribe, Structural Due Process, 10 Harv. C.R.-C.L. L. Rev. 267 (1975); H. Hart \& A. Sacks, The Legal Process: Basic 
In the competing view, law is seen as both autonomous of society and a function of it. Substantively, legal norms are less formal than rules but more formal than organic social norms: their characteristic form is the standard, a norm that requires an individualized assessment of how a social goal can best be furthered in a particular case. Procedurally, the norms are legitimated through enactment by specialized institutions, but participation in enactment is broadened by delegation of power to social groups and by the incorporation of social norms into the promulgated law. The distinction between enactment and enforcement is attenuated; it is expected that substantive norms will be elaborated and developed in the process of enforcement.

The most characteristic feature of the organizational structure that the competing vision associates with this type of legality is the profession. The profession plays the role in the opposed vision that the aristocracy played in classical political theory and the civil service played in Hegel's political theory; it mediates between legality and society. This role is best expressed in Hegel's notion of the "universal class." The reference to class suggests that the profession is differentiated from other groups within organic society, but also that, to a far greater degree than the Weberian bureaucracy, it is immersed in society. On the other hand, the reference to universality suggests that the profession aspires to rise above the conflicting interests and particularistic orientations of other classes.

This organizational structure differs from the dominant vision in that it is more decentralized and prescribes a higher degree of education, skill, status, and reward for front-line decisionmakers. Decentralization is associated with the relatively diffused character of sovereignty in the opposed vision. Since sovereignty is not embodied in a unitary actor or institution, it cannot be organized as the apex of a hierarchical bureaucracy. Moreover, the commitment to relatively individualized judgment under standards requires autonomy on the part of the decisionmaker to respond to the contingencies of the particular case. Hierarchical review is limited by the inability of reviewers to know the full range of information on which the initial decisionmaker acts. In addition, decentralization is required to make possible meaningful participation by citizens affected by the decisions. The importance of such participation arises from the attenuation of the differentiation of law and of the distinction between enactment and enforcement. Since citizens have information and views that are valuable

Problems in the Making and Application of Law (1958) (unpublished manuscript). In the area of welfare this perspective has been applied to judicial review and administrative appeals, but rarely to the front-line administrative work force. See Mashaw, supra note 113; Rosenblatt, Health Care Reforms and Administrative Law: A Structural Approach, 88 YALE L.J. 243 (1978). Two broadly theoretical accounts of welfare administration which analyze some features of the opposed vision are $J$. Mashaw, Bureaucratic Justice (1983); P. NONET, ADMinistrative Justice (1969). 
to the decisionmaker, participation secures the benefit of this information and these views. Moreover, such participation gives the decisionmaker an opportunity to justify the decision to the citizen as an expression of legal norms rather than of individual will; it also enables the legal system to express a respect for the citizen that mitigates the socially centrifugal effects of adverse decisions. Such participation requires limited review because the more review restricts the decisionmaker whom the citizen actually confronts, the more attenuated becomes the citizen's participation in the decision.

The argument for the education, status, and reward associated with professionalism is that, first, since under a regime of standards decisions cannot be mechanized, they will require complex and reflective judgment for which extensive training is needed; second, given the impossibility of coordination and control through formal rules and hierarchical supervision, coordination and control must come through self-control instilled in the course of professional socialization, through the continuing collective elaboration and development of norms in the professional culture, and through collegial peer pressure; and third, high status and reward are needed to attract sufficiently able people and to maintain the confidence of the citizenry in the system.

Here then are the answers of the opposed vision to the questions raised by the issue of discretion. The answer to the question of value is that standards for the assessment of the conduct of public officials are those elaborated collectively by professional officials and developed in decentralized enforcement proceedings in which citizens participate. The answer to the question of trust is that public officials can be trusted to adhere to applicable standards when they are socialized through professional training to do so, when they are active participants in a vital professional culture, when they are subject to pressure from peers to do so, when they have a duty to justify their decisions to citizens affected by them, and when they receive relatively high status and reward.

The opposed vision sees a limited but important degree of shared values and relations of trust in the society. The common goals of order on which the society is founded are somewhat more concrete than in the dominant vision. Efficiency means, not only a general goal of coordination, but more specific goals (for example, high GNP, clean environment); freedom means not only a general autonomy to pursue subjective ends, but the social guarantee of specific personal interests (for example, privacy, access to justice, minimum needs); and fairness means, not only a general prohibition of favoritism, but also specific requirements of similar treatment and prohibitions of different treatment (for example, "suspect classifications"). The greater degree of shared values and trust in the society both 
requires and makes possible a greater degree of individuation and participation in the legal system.

The opposed vision responds to the first of the problems of communication-imprecision-by trying to achieve a tighter fit of decisions to goals through a legality of standards, through decentralized organization permitting flexible response to the contingencies of particular cases, and through professional decisionmakers who can be trusted to elaborate and apply the standards in accordance with their purposes. Its response to the problem of overload lies in its notion of professional doctrine as a manageable body of basic principles and methods that, once mastered, can generate decisions in an infinite number of particular cases. Professional doctrine thus obviates the need to provide explicit rules to govern every foreseeable case.

The response to the problem of indeterminacy is more complex. The opposed vision does not identify order with the enforcement of a differentiated set of formal substantive rules. It recognizes that substantive rules are indeterminate and holds that they must be elaborated progressively in individual cases. It also recognizes the enforcement dimension of indeterminacy and holds that the legal norms must be qualified and mediated by a variety of procedural norms and institutions, as well as by non-legal practices and institutions. It responds to the dialectic of legal and other social norms with theories about when legal norms should have priority (for example, where basic rights of discrete insular minorities are at stake, where a particular commercial group in its dealings with consumers or strangers has lagged behind the moral or technical standards of the rest of the society) and when non-legal social norms should prevail (for example, in dealings between businessmen), and with balancing methods for reconciling conflicts.

The opposed vision aspires to provide the citizen a genuine understanding of the norms that affect her. It purports to achieve this goal through the individual's direct participation in proceedings that affect her and through relatively individualized communication by decisionmakers or professional advocates.

The opposed vision responds to the problems of supervision by reducing supervision to a secondary role and relying on peer relations and socialization, supplemented by citizen participation, as its primary means of organizational control.

It responds to the problem of worker alienation by trying to engender official commitment to the purposes of the system through professionalism. It responds to the problem of citizen alienation by encouraging citizen participation in the elaboration of the norms of the system, by taking some account of concrete personal goals and characteristics in substantive 
norms, and by promoting reflective and informed citizen choice through the provision of enforcement resources. The opposed vision recognizes that the citizen's understanding of her own purposes may be affected by the legal system. Indeed, the legal system is designed to affect the litigant by encouraging a sense of solidarity. But the system is also designed to encourage autonomous decision through measures such as rules disfavoring specific types of superficially solidaristic choices (for example, guilty pleas) that seem unlikely to be genuinely autonomous, and procedures designed to provide information and assistance and to secure participation.

The opposed vision also aspires to mute the organizational paradox of formality. By diffusing sovereignty and attenuating the distinction between enactment and enforcement, the system tends to discourage appeal beyond constituted authority to the sovereign will, as the citizen herself interprets it. Citizen participation in a process involving both enactment and enforcement limits the sense of distance from the sovereign and the dangers of disorder and unfairness it creates.

Considered as an alternative to the dominant vision in welfare administration, the opposed vision is subject to at least two types of criticism. One type arises from within the literature of the opposed vision. Except for the relatively modest and supervised participation afforded citizens, the vision of public work arrangements premised on shared values and trust in the opposed vision is limited to a specific group, the professional class. The literature of the opposed vision generally assumes and occasionally (as in the recent writing expressing anxiety about the growth of the federal judiciary ${ }^{\mathbf{1 1 7}}$ ) asserts that this group is necessarily a small one and that the possibilities for its expansion are limited. Some believe that the limit has already been exceeded; in any event, the expansion of professionalism that would be required to implement the opposed vision at the lower tier of the public work force would surely-the criticism asserts-exceed the limit.

A second set of criticisms arises from outside the opposed vision. ${ }^{118}$ It denies that decentralized professional organizations can achieve controlled, coordinated enforcement in any manner that could be interpreted as expressing or implementing the goals of social order. It asserts that the doctrines and practices of those who appeal to the opposed vision express, not the interests of the larger society, but the group interests of the professionals themselves and/or their patrons and clients.

A related but more tentative criticism would suggest that the under-

117. See H. Friendly, Federal JuRISDiction: A General View 28-31 (1973); McCree, Bureaucratic Justice: An Early Warning, 129 U. PA. L. REV. 777 (1981).

118. See Brest, The Fundamental Rights Controversy: The Essential Contradictions of Normative Constitutional Scholarship, 90 YALE L.J. 1063 (1981); Tushnet, Truth, Justice, and the American Way: An Interpretation of Public Law Scholarship in the Seventies, 57 TEX. L. REV. 1307 (1979). 
standing of shared values and trust is, not so much implausible, as ambiguous. Sometimes the opposed vision speaks of shared values and relations of trust as if they were embodied in established social institutions and practices. In these instances, it tends to take hierarchy for granted or to interpret it as a social necessity. But at other times, it speaks of shared values and trust as if they were ideals to be realized through the transformation of established social institutions and practices. In these instances, it tends to be suspicious of hierarchy or to interpret it as a social failure.

Consider the response of the opposed vision to developments such as the welfare enforcement activities of the 1960's and 1970's, in which established institutions were strained by the large-scale assertion of previously unenforced norms. Unlike the Weberian view, the opposed vision does not assume that order depends uniquely on the enforcement of the norms. It can see in these developments a conflict between the redistributive and humanitarian goals expressed in the substantive norms on the one hand and a variety of other goals embodied in established institutions (for example, fiscal economy, preservation of labor incentives) on the other. At this point, the ambiguity appears. One tendency of the opposed vision is to suggest that officials limit substantive enforcement to moderate the strain on established institutions. But another tendency suggests that characteristics of the particular substantive norms involved-the fact that they concern basic needs of disadvantaged people-warrant enforcement even at the cost of strain on other social goals.

I want to postpone final assessment of these criticisms in order to turn now to a prominent set of arguments designed to reconcile the dominant and opposed visions in public law.

\section{Separation of Powers/Combination of Functions}

I have been discussing the two visions of legality and organization as if they were mutually exclusive. In fact, however, most contemporary legal thought attempts to make room for them both. Indeed, the liberal legal scholarship of the 1960's and 1970's made notable efforts to develop both. At the same time that the liberals were arguing for the elimination of the discretion (informality, decentralization, professionalism) of welfare workers on the grounds that the rights they enforced were vital and the rightholders vulnerable, they were arguing for the expansion of the discretion of federal judges on precisely these grounds. While in the former effort they consistently conflated informality and decentralization with arbitrariness, in the latter, they produced an enormous literature vindicating the notion that a standards jurisprudence and a decentralized judicial organization could produce-1ndeed was required to produce-coherent, rational decisionmaking. 
In this effort the two visions have been mediated by notions of separation of powers or combination of functions that suggest that they can be institutionalized so as to complement each other. The aspect of the separation of powers most pertinent here distinguishes between ministerial administrative tasks and judicial tasks; it associates the vision of rules, hierarchy, and proletarianism with the former, and the vision of standards, decentralization, and professionalism with the latter. This mediating project calls for an interpretation that permits the characterization of different enforcement decisions as ministerial or judicial. Such distinctions have never been stable; the understanding of the administrative-judicial distinction worked out early in this century has been repeatedly upset by the growth of the regulatory-welfare state. ${ }^{119}$ For example, in important respects, the job of the welfare worker seems the same as that of the federal judge: both make decisions about claims of individual right which are governed by complex state and federal laws and involve potentially complex factual judgments.

There are two overlapping approaches to characterizing enforcement work for the purposes of separation and combination. One assumes that both modes of decision are applicable to all substantive areas but that within each area different decisions lend themselves to one or the other mode. The other assumes that certain substantive areas lend themselves generally to one or the other mode of decision.

Internal Differentiation: Routine Cases v. Trouble Cases. The first type of interpretation emphasizes the separation and combination of judicial and ministerial enforcement within the welfare system. It is reflected not only in the way the courts have defined their own roles in relation to administrators, but also in the internal development of administration.

One response of the welfare managers to the efforts of advocates and the courts to expand the procedural rights of recipients has been to increase the differentiation and separation of nominally ministerial from nominally adjudicatory functions within the system. The trends toward legalization, bureaucratization, and proletarianization have been accompanied by the promotion of small, marginal sub-bureaucracies with nominally judicial functions in which concessions are made to individualized judgment, decentralization, and professionalism. One manifestation of this structure is the codification of systems of dual law in which the "workers" are required to make decisions only on the basis of the voluminous sublegal instructional materials that purport to break down the prescriptions of the statutes and regulations into routine mechanical operations, while

119. See M. Vile, Constitutionalism AND the SEPARATion OF POWERS 29-32, 86-88, 280-90 (1967); Arnold, The Role of Substantive Law and Procedure in the Legal Process, 45 HARV. L. REV. 617, 624-31 (1932). 
the hearing "officials" are expected to make decisions by directly referring to and interpreting the more general norms of the statutes and regulations. ${ }^{120}$

The system is designed so that adjudicatory decisionmaking has no effect outside of the particular cases appealed on the nominally administrative functions. For example, most programs repudiate the principle of stare decisis in the appeal procedure. The consequence is to limit collegiality among the hearing officials, and more indirectly but more importantly, to preclude the development of a sense of autonomy and responsibility among the workers. The workers are taught that a reversal of one of their decisions is not to affect their future conduct. They have no duty to consider or distinguish it; they may not regard it as a precedent; it is simply not a comment on their work. The message (well understood by the workers I have talked with) is that procedures in which decision depends on complex judgment, in which clients participate actively, or in which decisionmakers enjoy autonomy and status have nothing to do with the front-line worker's job. ${ }^{121}$ A further instance of the segregation of nominally administrative and judicial functions results from a change in recruitment patterns. Under the old regime, hearing officers were recruited from front-line workers or from administrators. In the new regime, they tend to be recruited from outside the system, often from law schools.

This internal administrative differentiation of functions, as well as the parallel differentiation between the adminstration as a whole and the courts, seems to rest on a distinction between routine cases and "trouble" cases. Routine cases are appropriate for ministerial decision; trouble cases for judicial decision. All cases are determined ministerially first; trouble cases are identified and channeled into the judicial sphere when claimants initiate appeals. ${ }^{122}$

One variation of this distinction understands routine cases as those in which there is no dispute between the administration and the claimant and trouble cases as those in which there is a dispute. On this view, the primary enforcement role is ministerial; the function of judicial decision is to resolve disputes. This view explains the administrative design that min-

120. On the differences in the norms applied by eligibility workers and hearing officials, see The Bellmon Report, supra note 15, at 12-15; B. Hecker \& T. Nelson, AFDC Fair Hearings: A Study of Administrative Due Process (Legal Servs. Inst. 1981) (unpublished manuscript on file with author); Lissner, Escalating State Agency Denial Rates and Their Impact on OHA, OHA L. REP., Apr. 1980, at 40 .

121. A more extreme degree of separation is achieved in systems such as Social Security, Unemployment Insurance, and a few state welfare programs in which the worker does not even appear at the hearing. The administration's case is presented by a full-time representative, or the hearing officer undertakes to develop both cases.

122. See H. Hart \& A. Sacks, supra note 116, at 312. 
imizes the impact of judicial decision on unappealed cases: The judicial function has no role where there is no dispute. The problem with this view is that whether a case is disputed or not is a function of organizational structure. If the ministerial sphere encourages requests for benefits, effectively communicates to claimants about their rights, effectively enforces hearing rights, and provides advocacy resources, it will generate a great number of trouble cases. If the system maintains or exacerbates claimant inhibitions about requesting benefits, fails to communicate about rights, fails to enforce hearing rights, and provides no advocacy resources, it will generate few trouble cases. The critique of the Weberian view suggests that the factors that determine which cases are disputed will be to an important extent arbitrary in relation to the goals of efficiency, freedom, and fairness.

Another variation understands the routine/trouble distinction in terms of relative difficulty. Judicial decision is considered more reliable than ministerial decision, but in the ordinary or easy case, there is a relatively high probability that ministerial decision will reach the same result as judicial decision. Since judicial decision is thought more expensive, it is most expedient to reserve it for the more difficult cases. This view suffers from a problem similar to that of its predecessor. The system depends on claimant initiation of appeals to distinguish hard from easy cases. ${ }^{123}$ Given the problems of communication and alienation, the factors that determine which cases are appealed may be to a significant extent arbitrary in relation to probability of reversal on appeal. In most public assistance programs, reversal rates for appealed cases tend to be substantial but appeal rates, low. ${ }^{124}$ If one could believe that most hard cases were in fact channeled into the appeal process, one might interpret the low appeal rates as a vindication of the ministerial function and the substantial reversal rates as the normal consequence of review of hard cases. But both intuition and the scant data that bear on the question suggest that the premise is incorrect. It appears that a large but indeterminable number of cases that would be reversed are not appealed by claimants because they lack under-

123. A variety of administrative review or quality control procedures have been developed that seek ministerially to distinguish easy from hard cases in order to focus enforcement resources on the latter. See J. MASHAW, C. GOETZ, F. GOODMAN, W. SCHWARTZ, P. VERKUIL \& M. CARROW, SOCIAL SECURITY HEARINGS AND APPEALS 14-15, 22-24 (1978). These methods are highly formal and hence suffer from the liabilities of formality. Nevertheless, they appear to have some promise, and I suggest below that they might supplement a variety of more fundamental reforms. See infra notes 176-77.

124. Mashaw estimates that in the first six months of 1971 only $2 \%$ of all appealable decisions in public assistance programs were appealed and that more than half of these appeals were in only three states. Mashaw, supra note 67 , at $784 \&$ n.33. Reversal rates vary widely but are usually substantial for example, $42 \%$ of the AFDC appeals decided at hearing (that is, not settled or abandoned) in fiscal year 1980 were decided in favor of the claimant. U.S. DEP'T OF HEALTH, EDUC. \& WELFARE, QUARTERLY PUblic Assistance STATISTICS, Jan.-Mar. 1981, at 22. 
standing of the rules, because they are unable to negotiate the appeal procedures, or because the administration fails to enforce the appeal procedures. ${ }^{125}$

Another problem with the hard/easy case distinction is that the category of easy cases may not be large enough to justify the ministerial function. It may be that in many areas of welfare, most claims will look different under informal than under formal norms and that, given an appropriate degree of informality, most will look different when reconsidered by an autonomous and better educated decisionmaker under a procedure that affords more opportunity for claimant participation. This is one interpretation of the crisis of the Social Security Administration disability programs, which are among the few income maintenance programs with high appeal rates. Despite high appeal rates, the programs have also had high reversal rates. From 1975 to 1980, when, apparently as a result of increasing formalization and bureaucratization of the ministerial decision process, the appeal rate increased from $52 \%$ to $69 \%$, the reversal rates also increased, from $49 \%$ to $58 \% .{ }^{126}$ If, as seems likely, the reversal rates would remain high at an even higher appeal rate, it seems questionable whether there would be enough easy cases to justify the ministerial role even if there were some ministerial way of distinguishing them from the hard cases.

External Differentiation: Desert v. Efficiency. The other approach to the separation of powers and the combination of functions is to try to assign claims to one or the other type of legality and organization in terms of the type of substantive norms they involve. Most frequently, the opposed vision is associated with norms implicating individual desert, while the dominant vision is associated with norms implicating social efficiency. And the claims characterized in terms of desert usually turn out to be private law claims, while those characterized in terms of efficiency usually include welfare claims.

125. The data include a survey of denied applicants in Virginia indicating that many who appeared eligible did not appeal, surveys of recipients showing that most appear to have insufficient knowledge of appeal rights to make effective use of them, and a 1972 study of New York indicating substantial failure to implement hearing rights for those who file appeals. See Handler, supra note 69 , at 54-69.

Several studies of unappealed Social Security disability cases suggest that a substantial percentage would have been reversed if they had been appealed. S. NAGI, DISABILITY AND REHABILITATION (1969); Mashaw, supra note 113, at 44-45 (describing Government Accounting Office study); The Bellmon Report, supra note 15.

126. Lissner, supra note 120, at 44; The Bellmon Report, supra note 15, at 9 . The appeal and reversal rates apply to denied claims appealed from the second stage of administrative determination (reconsideration) to the ALJs. The rates of claims denied at the initial administrative stage reaching and reversed by the ALJs are considerably smaller. The appeal rate figures apply to both Social Security and Supplemental Security Income disability claims; the reversal rate figures only to Social Security and concurrent claims. 
Although few who invoke such distinctions these days try to defend them systematically, this type of argument has a long history. That history, however, does not suggest promise for current efforts to defend the distinctions. Distinctions between private law claims and claims by beneficiaries of public regulatory or welfare activities were fundamental to the classical liberal legalism of the substantive due process era. Private law claims were matters of individual right because they were defined by a basic social process - the self-regulating market-which could be deduced from a morally fundamental conception of individual autonomy. A claim of right asserted an infringement of individual autonomy; its vindication restored a preexisting distributive equilibrium. Since judicial enforcement was the paradigmatic mode of rights enforcement, it was the appropriate one for private law claims. On the other hand, claims by beneficiaries of regulatory or welfare programs were matters of policy. These government activities involved collective coercion to re-distribute wealth, which though not necessarily impermissible, was suspect because of its threat to individual rights. Since beneficiary claims were not rights, their enforcement raised only issues of social convenience.

Much of the liberal jurisprudence of this century has been devoted to dismantling this view, especially its emphasis on the distinction between private and public claims. First, liberals showed that the private law regime of the classicists did not follow from the classicists' concept of individual autonomy, that private law was in fact as riven with policy considerations and as coercively redistributive as any welfare activity. Second, they showed that a broad range of welfare beneficiary interests was as consistent with the classicists' notion (as well as with some more plausible notions) of individual autonomy as any private law claim. As a consequence of these efforts, almost every area of American legal culture is characterized by controversies involving the assertion of values of both individual desert and efficiency. ${ }^{127}$

Against this background, the project of vindicating some combination of the two models of legality and organization in terms of classification based on the private/public, individual/social efficiency distinction does not seem promising. Nevertheless, the project seems lately to have tempted both conservatives and liberals. The project is implicit in two types of arguments; one makes the distinction in terms of the underlying moral concerns of private and welfare claims; the other, in terms of the volume of claims.

An example of the first type is the suggestion that private law claims

127. Cohen, Property and Sovereignty, 13 CORNell L. REV. 8 (1927); Pound, A Survey of Social Interests, 57 HARV. L. REV. 1 (1943); Reich, supra note 69. 
tend to invoke concepts such as "fault," which express a judgment on the moral character of the litigants, while welfare claims, which are generally premised on need, do not involve such personal moral judgment. Judicial enforcement, with its greater capacity for individuation and litigant participation, is said to be more appropriate for decisions expressing personal judgment. ${ }^{128}$ This suggestion seems factually mistaken. Private law is pervaded by non-fault deterrent and distributive principles that do not imply judgment on moral character. ${ }^{129}$ (In the years since Roscoe Pound proposed negligence as the paradigmatic moral judgment norm, the law-andeconomics writers have restated just about every variation on the negligence principle in social efficiency terms.) And even the reformed welfare system is pervaded by considerations of fault and moral character. (In some programs, the applicant must show "good cause" for not being selfsupporting; in others, more formal criteria, such as disability or "absence of a parent from the home," stand as proxies for such determinations.) $)^{\mathbf{1 3 0}}$

The second type of argument for external differentiation is less well formulated but far more pervasive. It is signaled by anxious concern with the volume of welfare claims. For some, this concern is so intense, and the factor of volume so dispositive, that the mere incantation of phrases like "mass justice," amplified, if at all, by recitations of the number of welfare applications or appeals and vague references to cost or efficiency, is sufficient to justify almost any measure of formalization or bureaucratization of a welfare program. ${ }^{131}$ The argument underlying this rhetoric seems to be that (a) efficiency is a distinctively important concern with welfare claims because they have a relatively high volume, and (b) enforcement procedures characterized by formality, bureaucracy, and proletarianism are presumptively more efficient.

None of the recent expressions of this argument is persuasive. For one

128. Mashaw, Confict and Compromise Among Models of Administrative Justice, 1981 DUKE L.J. 181; see R. POUND, AN INTRODUCTION TO THE PHILOSOPHY OF LAW 68-71 (rev. ed. 1958). Neither Mashaw's nor Pound's deservedness/efficiency distinctions coincide with the conventional private/public distinctions, but both draw their deservedness examples from private law, and Mashaw uses a public assistance program (food stamps) to exemplify social efficiency.

129. See Kennedy, Distributive and Paternalist Motives in Contract and Tort Law, with Special Reference to Compulsory Terms and Unequal Bargaining Power, 41 MD. L. REV. 563 (1982); see also R. WASSERSTROM, THE JUDICIAL DECISION: TOWARD a THEORY OF LEGAL JUSTIFICATION 98-105 (1961) (criticizing Pound's distinctions).

130. 42 U.S.C. $§ 5606$ (a) (1976) (absence of a parent in AFDC); Liebman, supra note 90 (elements of moral judgment implicit in disability standards).

Even where the legislative concern can be characterized unambiguously as efficiency, the values of the rule of law expressed in the due process clause and throughout the legal culture limit the extent to which a legislature may pursue efficiency at the expense of individual deservedness concerns. As Mashaw has observed, given these values, individual deservedness concerns are relevant to any legal issue. Mashaw, supra note 113 , at $48-49$.

131. R. DIXON, supra note 69; Califano v. Boles, 443 U.S. 282, 283-87 (1979) (Rehnquist, J.); Friendly, Some Kind of Hearing, 123 U. PA. L. REV. 1267, 1298, 1301 (1975). 
thing, they do not specify the baseline to which the volume of welfare claims is being compared. If the focus is on initial welfare claims, the relevant comparison would seem to be the volume of initial private law claims (most of which of course are made to private parties), or perhaps some sub-category of welfare such as social insurance should be compared to a private law sub-category, such as private insurance. If the focus is on welfare appeals, then the appropriate comparison probably would be some set of private judicial claims. Neither intuition nor any data I know of suggests that, on any of these comparisons, welfare claims are more voluminous than private claims. Moreover, a plausible argument about efficiency should consider, not simply volume, but the magnitude of the stakes or benefits involved in the claims. ${ }^{132}$ It is very hard to see on efficiency grounds why, for example, Justice Rehnquist should find enforcement expense a distinctively important concern in the Social Security system ${ }^{\mathbf{1 3 3}}$ (in which the average monetary value of a disability claim exceeds $\$ 30,000$ ) when enforcement expenses in many private law areas are probably far higher absolutely and relatively to the stakes involved. ${ }^{134}$ Of course, the dollar value of the average public assistance claim is far less than that of the Social Security disability claim and may well be less than that of the average private law claim (at least if we exclude "small claims"). But unlike most private law claims, most public assistance claims are a matter of basic subsistence to the claimant. If the comparison is made in terms of subjective value, magnitudes of stakes seem unlikely to justify emphasis on administrative cost in welfare.

More importantly, even if one accepts the premise that volume is higher and efficiency more important in the welfare area, it simply does not follow that formalization, bureaucratization, or proletarianization are more

132. Mashaw, Administrative Due Process as Social-Cost Accounting, 9 HoFsTRA L. REv. 1423 (1981)

133. Califano v. Boles, 443 U.S. 282, 283-87 (1979) (Rehnquist, J.) (because of volume, efficiency is basic concern in Social Security)

134. Mashaw, supra note 30 , at 824 , reports that in 1979 the monetary value of Social Security disability claims averaged $\$ 30,000$ and enforcement costs averaged $\$ 500$ per case.

I do not have either the data or the theoretical framework for a systematic comparison of welfare and private law claims, but the studies emerging from the Rand civil litigation research project tend to reinforce my intuition that the relative emphasis on efficiency in welfare, as opposed to private law, is unjustified. For example, the Cook County, Illinois, study concludes that " $t$ the amount in dispute in most Cook County trials is almost certainly less than the combined costs to taxpayers and parties" of processing the claims. M. Shanley \& M. Peterson, Comparative Justice: Civil Jury Verdicts in San Francisco and Cook Counties, 1960-1979, at 2 (Rand Inst. for Civil Justice, Working Draft, Mar. 1983); see also J. Kakalik and A. Robyn, Costs of the Civil Justice System, at xv (Rand Inst. for Civil Justice 1982) (average expenditures for jury trials in tort cases estimated between $\$ 2790$ and $\$ 12,035$, depending on jurisdiction and case type).

Despite such indications, the "mass justice" writers sometimes seem to be as indifferent to efficiency in private law as they are obsessed with it in welfare. See Parklane Hosiery Co. v. Shore, 439 U.S. 322, 338 (1979) (Rehnquist, J.) (expressing "nagging sense of unfairness" about Court's application of collateral estoppel to deny corporate defendant a second judicial trial on fraud defense). 
appropriate. Whatever the resource constraints are, they will limit enforcement options, but at any given level of resources, there will be a spectrum of options that will range from relatively formal, bureaucratic arrangements to relatively informal, decentralized ones. Even at low levels of resources, there is no warrant for presuming that formality and bureaucracy will be more efficient.

It may often be true, as the argument from volume asserts, that accurate decisionmaking-that is, decisionmaking that conforms to the norms-takes less time when the norms are formal. ${ }^{135}$ But the relevant measure of efficiency is not the extent to which decisions conform to the norms, but the extent to which they promote the purposes of the program. As I emphasized above, formal norms have built into them a substantial discrepancy with the program's purposes. As AFDG Quality Control illustrates, accurate decisionmaking is not necessarily efficient decisionmaking. ${ }^{136}$ And it may also often be true, as the argument from volume emphasizes, that a given level of resources will support a larger number of clerical than professional workers. But if professionalism improves the quality and/or quantity of decisions, a smaller, number of professionals may well be more efficient than a larger number of clerks.

To presume simply because of volume and scarcity that we should prefer clerks to professionals in welfare is no more rational than to presume because of these factors that we should prefer orderlies to doctors in a medical emergency. Indeed, the example of medical triage shows that volume and scarcity may increase the efficiency of complex, informal judgment, decentralization, and professionalism. Triage connotes a dimension of enforcement decisions that is quite pertinent to the job of welfare workers and other street level public servants such as police officers. The Weberian view tends to see enforcement decisions as simply distinguishing between valid and invalid claims. But in triage situations, there are insufficient resources to enforce all the claims that are recognized as valid. Triage decisions thus involve, in addition to distinguishing valid from invalid claims, deciding which claims among the valid ones will be enforced. ${ }^{137}$ In the medical triage situation, the stakes involved in claims are high but vary widely in accordance with diverse circumstances. The imprecision costs of formality tend to be high; the information needed for supervision is costly or impossible to get; concerns about worker and claimant alienation are intense. The circumstances that make informality,

135. But see supra p. 1228 (on problem of normative overload).

136. See supra pp. 1210-13, 1226-28.

137. This feature of public service work is emphasized in M. LIPSKY, supra note 71; J. WILSON, VARIETIES OF POLICE BEHAVIOR (1968). The critical factor of scarcity in public assistance work concerns advice and assistance. 
decentralization, and professionalism valuable in medical triage are shared to a lesser but important degree in public assistance. ${ }^{138}$

If medical triage seems too exotic an analogy, consider the enforcement systems of private insurance companies, which handle high volumes of claims and seem likely to have been designed with some view to minimizing costs. As described by Laurence Ross, ${ }^{139}$ they involve a high degree of informality and decentralization apparently because of the problems of close supervision, worker alienation, and claimant (customer) alienation.

Thus, the arguments for external differentiation have not been plausibly sustained.

\section{Class}

If the preceding argument is correct, one cannot account for the course of welfare jurisprudence and welfare reform in recent years in terms of the general goals of efficiency, freedom, and fairness and the general conditions of modern society. One has to look to more concrete social and historical contingencies. The most interesting of these contingencies are variations on the theme of class.

Although explicit reference to class is considered vulgar in legal professional circles, a vague but important set of assumptions about class lies beneath (and sometimes even above ${ }^{\mathbf{1 4 0}}$ ) the surface of most contemporary public law discourse. These assumptions tacitly mediate the simultaneous tendencies of public law discourse to deny and affirm the possibility of organization premised on shared values and trust. To put it crudely but not unfairly, organization premised on shared values is considered possible as long as the values are those of elite professionals; organization premised on trust is considered possible as long as those to be trusted are elite professionals.

Thus, one way to interpret recent welfare jurisprudence is as an expression of the efforts of professionals to define their place and relationships in the course of the recent expansion of the welfare state. Legal doctrine has played a role in the structuring of class relations within the welfare state that overlaps and parallels the role of technological doctrine in structuring relations in the private economy. For example, the role of

138. The susceptibility of the poor to crisis and emergency, arising in part from inability to make financial provision for the future, is often portrayed as the central characteristic of the "culture of poverty." See E. LIEBOW, TALLY'S CORNER: A STUDY OF NEGRO STREETCORNER MEN (1967).

139. L. ROSS, SETTLED OUT OF COURT 32-33, 45-66, 96-116 (1970). Ross describes the approach to claims determination of the adjusters that he observed as "principled contextualization of fairness." Id. at 52 . He also suggests that the adjusters view their role as that of providing advice and assistance to claimants in accordance with relatively complex distributive judgments. Id. at 46-47, $52-54$.

140. See Neuborne, supra note 116 , at 1126. 
the legal distinction between enactment and enforcement in rationalizing the boundary between professional policy and judicial officials on the one hand and ministerial officials on the other in the public sphere seems analogous to that of the technical distinction between conception and execution that rationalizes the boundary between elite managers and workers in the private sphere. ${ }^{141}$

The issue of class with which welfare jurisprudence has been most concerned is situating the large number of service roles created by the welfare expansion of the 1960's and 1970's. ${ }^{142}$ This expansion involved roles that, at various points since the beginning of the welfare state, have seemed ambiguous both in their functional definition and their position in the social hierarchy. Many of them implicated occupations such as social work, nursing, and teaching, which have long claimed professional status but with mixed success. In these fields, the gap between aspiration and reality has at times inspired attempts at redefining the functional content and social status of occupational role. In the 1960's and 1970's, the expansion of welfare activity, the demand for institutional reform, and the creation of new contexts of practice temporarily unsettled the definitions of a variety of these service roles. Jurisprudence contributed to the resolution of this indeterminacy in favor of a proletarian definition of the welfare worker's role.

There are at least two promising approaches to interpreting this development; one emphasizes the constraints of social structure, the other the limited goals of the liberal welfare politics of the 1960's and 1970's. The two approaches are not really distinct. Social structure is simply congealed politics. Whether one explains events in terms of social structure or politics depends on whether one regards society as relatively open to purposive transformation (so that social structure appears as a transitory manifestation of collective action) or as relatively closed to such transformation (so that social structure appears as a fixed limit on collective action). ${ }^{143}$ Thus, whether one regards the two approaches as mutually exclusive or as complementary depends on where one draws the line between social structure and politics.

141. See H. BRAVERMAN, LABOR AND MONOPOLY CAPITAL 85-138, 184-235 (1974).

142. On the expansion of white collar service and governmental work roles during this period, see Freeman, The Evolution of the American Labor Market, 1948-80, in THE AMERICAN ECONOMY IN TRANSITION 349, 362-66 (M. Feldstein ed. 1980); on the ambiguous status of some of these roles, see Scott, supra note 22.

On the parallel developments in the intermediate level roles in health care and education during the past two decades, see A. WISE, LEGISLATED LEARNING: THE BUREAUGRATIZATION OF THE AMERICAN ClassROOM (1979); Kanter, Work in a New America, DAEDALUS, Winter 1978, at 47, 65. For an account of an earlier episode of formalization and bureaucratization in education, see D. TYACK, THE ONE BEST SYSTEM (1974).

143. I owe this conception of politics to Roberto Mangabeira Unger. 


\section{A. Social Structure}

The approach based on social structure explains the triumph of the dominant vision by asserting that social structure precludes the downward extension of professionalism that would be required by the application of the opposed vision to welfare administration. This interpretation rests on the view of class implicit in contemporary public law discourse.

At the center of this view stands the professional class. The professional class is distinguished from the class above it (the upper class) by relatively lesser wealth, power, and status, and from the classes below it (the working class and the poor) by relatively greater wealth, power, and status. It is distinguished from all the other classes by a distinctive ethical orientation toward work. This orientation is expressed in the premise of universality in Hegel's notion of the "universal class."144 It views work as expressing and implementing values that rise above the competing ends of antagonistic individuals and groups. It repudiates the ideal of work as instrumental to the satisfaction of private ends or as a means of imposing one's will on the world and asserts an ideal of work as an intrinsically satisfying form of participation in the life of the community. It is this transcendent, universalistic orientation to work that requires and makes possible autonomy and responsibility in the organization of professional work.

This vision of class plays an important, though only partially explicit role in two prominent streams of contemporary legal thought: the legal process and the rights-and-principles schools. The legal process school emphasizes professionalism as part of the solution to the question of trust. ${ }^{148}$ It proposes to secure the goals of social order through fair procedures, and considers professional decisionmakers an essential part of such procedures. People are said to accept the decisions of such decisionmakers in disputed cases in part because they have confidence that their professional status is a guarantee of fairness. The rights-and-principles school looks to the professional class as part of the solution to the problem of value. It proposes to make legal norms determinate by interpreting them in the context of the discursive practices of a particular community. Although the rights-and-principles writers are notoriously vague about the boundaries of the community they are talking about, these boundaries

144. G. HEGEL, supra note 93 , at 188-93. For varying contemporary perspectives on the notion of a professional class, see E. BANFIELD, THE UNHEAVENLY CITY 48-54 (1970); H. GANS, THE URBAN VILLAGERS 229-62 (1962); A. GOULDNER, THE FUTURE OF INTELLECTUALS AND THE RISE OF THE NEW Class (1981); THE NEW Class? (B. Bruce-Briggs ed. 1980); Ehrenreich \& Ehrenreich, The Professional-Managerial Class, in BETWEEN LABOR AND CAPITAL 15-45 (P. Walker ed. 1979).

145. See Wellington, Common Law Rules and Constizutional Double Standards: Some Notes on Adjudication, 83 YALE L.J. 221, 248-49 (1973); H. Hart \& A. Sacks, supra note 116, at 117-78; Chayes, supra note 116, at 1307-08; Neuborne, supra note 116, at 1126. 
seem to be located within the confines of the professional class. ${ }^{146}$

There is, however, a second premise in this view of the professional class, the premise of exclusivity. This premise holds that the distinctive experience of transcendence and universality involved in professional work is necessarily limited to a small minority, that the rest of society is necessarily left to work roles in which the immediate experience is the pursuit of self-interest or group interest (however much the role occupants may convince themselves that in the long run such pursuit serves universal ends). The argument from social structure asserts that the possibilities for the expansion of professionalism are subject to severe limits.

There are two types of explanation of these limits. One sees them as structures of hierarchical privilege protected by patterns of defense on the part of the privileged and of acquiescence on the part of the unprivileged so entrenched as to be immune to political challenge. ${ }^{147}$ The other type of explanation sees the limits as functional adaptations to general constraints on social organization that could be altered only at the cost of leaving the society as a whole worse off. There are many variations on the functionalist explanation, some of which can be sampled in the recent literature lamenting the expansion of the federal judiciary. ${ }^{148}$ There is, for example, the explanation of cost, which asserts that further professionalization would require too many resources to adequately educate workers and structure their work setting in a manner consistent with professional norms. ${ }^{149}$ There is the explanation of aptitude and character, which asserts that professionalism depends on qualities of intelligence and fairmindedness that are in short supply. ${ }^{150}$ One version of this argument assumes that aptitude and character are innate and that everyone who has enough of them has already been recruited into the professional class. Another version assumes that at least character depends on childhood socialization and that lower class socialization handicaps people for professionalism by inculcating moral parochialism and an instrumental attitude toward work. ${ }^{151}$ There is the argument from size, which asserts that the

146. E.g., Fiss, Objectivity and Interpretation, 34 STAN. L. REV. 739, 746-47 (1982). The rightsand-principles writers show little interest in the beliefs of anyone other than legal professionals. Those who have investigated such beliefs have found important differences and discontinuities between the perspectives of those inside and those outside the professional culture. See F. PARKIN, CLASS INEQUAL ITY AND POLITICAL ORDER 79-102 (1971); Casper, Having Their Day in Court: Defendant Evaluations of the Fairness of Their Treatment, 12 LAW \& SOC'Y REV. 237 (1978); McCloskey, Consensus and Ideology in American Politics, 58 AM. POL. SCI. REV. 361 (1964); Sarat, Studying American Legal Culture: An Assessment of Survey Evidence, 11 LAW \& SOC'Y REV. 427, 435-41, 464-69, 471-77 (1977).

147. Cr. Ehrenreich \& Ehrenreich, surpa note 144, at 5.

148. See H. FRIENDLY, supra note 117; McCree, supra note 117.

149. See Scalia, The ALJ Fiasco-A Reprise, 47 U. CHI. L. REV. 57 (1979).

150. See McCree, supra note 117 , at $780,782-783$.

151. See E. BANFIELD, supra note 144, at 48-54; H. GANS, supra note 144. 
collegiality and peer relations required by professionalism can be achieved only within a small group. ${ }^{152}$ And there is the argument from differential status and reward, which asserts that professionalism is dependent on hierarchical status that would be diluted to the point of inefficacy by expansion: without differential status either the professional's motivation to perform would be diminished or she would lose the ability to inspire in others confidence in the validity of her decision. ${ }^{153}$

None of these arguments has ever been established or even systematically articulated, and none seems obviously correct on reflection. The privilege explanation usually turns out to be simply a description of the social structure coupled with an expression of vague skepticism about the possibility of changing it. The functional explanations tend to be more ambitious but not necessarily more plausible. The explanation of aptitude and character suffers from an inability to define the relevant aptitude or character and to measure its availability. This explanation is also challenged by evidence that people's moral and technical capacities vary significantly with the circumstances of their work-setting and are generally enhanced by conditions of responsibility and autonomy. ${ }^{164}$ As for cost, it may be that the added cost of educating and equipping professional workers could be offset by reductions in the costs of supervision or by savings through the more flexible and efficient deployment of resources that professionalism might make possible. Moreover, to the extent that there is a scarcity of educational resources, it is partly a function of the fact that many occupational groups-the legal profession is one I am sure of-are vastly overeducated relative to the demands of their jobs; to the extent that the professionalization of the lower tier public work force could be accomplished by redistributing resources from the overeducated groups, there would be no net cost. The explanation of size encounters the difficulty that the American welfare state is already fragmented into programs and organizational structures of widely varying sizes and degrees of specializa-

152. See Schwartz, The Reorganization of the Legal Profession, 58 TEX. L. REV. 1269, 1278-79 (1980).

153. H. FRIENDLY, supra note 117 , at $28-30$.

154. See C. SABEL, WORK AND POLITICS: THE DIVISION OF LABOR IN INDUSTRY (1982); see also Scott, supra note 22 (effects of education on attitudes toward work among welfare workers).

As Paul Bator puts it:

Competence and sensitivity are themselves not static phenomena. Conscientiousness, dedication, idealism, openness, enthusiasm, willingness to listen and learn . . . are at least to some extent evoked by a sense of responsibility, by the realization that one has been entrusted with a great and important task. I can think of nothing more subversive to the . . . inner sense of responsibility than the notion that, to the greatest possible extent, all the important shots will be called by someone else because we don't believe in his or her competence and sensitivity.

Bator, The State Courts and Federal Constitutional Litigation, 22 WM. \& MARY L. REV. 605, 624-25 (1981). Bator is arguing here that state judges are qualified to determine federal constitutional claims, but the point is applicable to the role of the welfare worker as well. 
tion; there is simply no reason to believe that whatever limits collegiality and peer relations impose on size could not be accommodated from among this broad variety of organizational structures. The explanation of differential status and reward appears to be contradicted by examples of lower status workers who seem to perform responsibly under conditions of autonomy ${ }^{155}$ and by indications that the high status of judges does not prevent people adversely affected by their decisions from feeling dissatisfied with them. ${ }^{168}$

But the basic problem with the argument from social structure is not the implausibility of the premise of exclusivity, but its incompatibility with the premise of universality. This problem is reflected in the basic ambiguities of the jurisprudence of the legal process and rights-and-principles schools: In the legal process school, are the decisions of the professional decisionmakers effective because they are substantively correct or because people acquiesce in them regardless of their substantive validity? To assert that they are always or usually correct would be inconsistent with the fact, acknowledged by the legal process writers, of widespread disagreement within the society and the professional class. ${ }^{157}$ But if the assertion is that they are effective merely because people acquiesce in them, then the legal process school seems to have betrayed the goals of efficiency, freedom, and fairness to the sanctification of mere stability and constituted power. ${ }^{158}$ In the rights-and-principles literature, are the values articulated by the professional class merely the contingent norms of this particular group, or are they universal (in at least the sense that they cut across divisions in the society) ${ }^{159}$ If the answer is that the rights-andprinciples literature has merely described the values of a particular class, then it has no plausible response to the question of value. But if the answer is that the values are universal, then the writers have to account for the fact that the values can be discovered only in the discourse of the professional class. The common problem of both approaches is the difficulty of reconciling the premise that direct experience of and responsibility to legal norms is possible only for a privileged minority with the premise that legal norms are universal in any meaningful sense. ${ }^{180}$

155. L. ROSS, supra note 139 , at $24-135$ (insurance adjusters).

156. Casper, supra note 146 , at $240-49$.

157. See Bator, Finality in the Criminal Law and Federal Habeas Corpus for State Prisoners, 76 HARV. L. REV. 441, 446-51 (1963).

158. See Gunther, The Subtle Vices of the "Passive Virtues," 64 ColuM. L. REV. 1, 1-13 (1964).

159. Compare Soper, Legal Theory and the Obligation of a Judge: The Hart/Dworkin Dispute, $75 \mathrm{MICH}$. L. REV. 473 (1977) (Dworkin's rights and principles are descriptive accounts of practices of particular community) with Fried, The Laws of Change: The Cunning of Reason in Moral and Legal History, 9 J. LEGAL STUD. 335 (1980) (Dworkin's rights and principles are universal).

160. See K. Marx, Critique of Hegel's Doctrine of the State, in EARLY WRITINGS 100-16 (R. Livingstone \& G. Benton trans. 1975) (arguing that Hegel's idea of universal class is self- 
A recent response to this problem combines themes from the legal process and rights-and-principles schools in a theory of adjudication that emphasizes dialogue and participation. ${ }^{\mathbf{1 6 1}}$ As in the legal process school, fairness is conceived in terms of procedure, but procedure is conceived here as the arena of an ongoing substantive discourse of the type described by the rights-and-principles writers. By emphasizing the professional decisionmaker's duty to listen to the arguments advanced by the litigant and to explain her decision in a manner responsive to these arguments, this view suggests that the professional can mediate between the universalistic moral culture that is her special province and the concerns of ordinary citizens. For the citizen, the judicial proceeding is an initiation into the universalistic moral culture; for the professional, the citizen's participation is a safeguard against excessive differentiation of the universalistic culture from the concerns of civil society.

I think this view rests on a naive understanding of how people experience judicial proceedings. ${ }^{162}$ But for present purposes, it is sufficient to emphasize how little the view promises, even within the framework of its own assumptions. The initiation it promises is merely a momentary ad hoc response to disputes that have found their way into the privileged forums of the professional decisionmakers. But few people ever enter these forums, and the factors that determine when and whether they do are to a large extent arbitrary in terms of the values of the universalistic moral culture. The setting in which most people, especially most poor people, confront the state is the bureaucratic setting of the lower tier public work force.

The argument from social structure against the downward expansion of the opposed vision thus has a depressing implication: At least for the poor, the experience of dignified, responsible, just treatment at the hands of the state must be a rare and random event. Except in those few and unpredictable moments when claims are precipitated into the privileged forums of the opposed vision, the experience of such people in their everyday dealings with the state must continue to be alienation and bewilderment.

\section{B. Politics}

The political approach interprets the dominant vision as ideology. By ideology I mean discourse that tends to portray as functions of fixed social structure what are in fact contingent political choices. As I use the term, it

contradictory).

161. Fiss, supra note 116; Mashaw, Administrative Due Process: The Quest for a Dignitary Theory, 61 B.U. L. REV. 885 (1981).

162. See Simon, The Ideology of Advocacy: Procedural Justice and Professional Ethics, 1978 WIS. L. REV. 29, 94-99; Sarat, supra note 146, at 441, 466-67. 
does not imply anything about the motivations of the people who engage in such discourse. Ideology is not necessarily propagated in bad faith; it is a kind of failed social theory. Nor do I mean to suggest that such discourse expresses the choices of a single class or group. Political choices typically reflect compromises or alliances among groups, and one use of ideology is to codify such compromises and alliances. The political interpretation of the dominant vision starts with the hypothesis that the liberal welfare jurisprudence of the 1960's and 1970's expresses such compromises and alliances. It proceeds by speculating about whether the groups involved-especially the liberal professional reformers and the lower-tier public work force-might have understood their interests and options in a way that made the reforms prescribed by the dominant vision seem a plausible political choice.

The political posture of the professional class toward the welfare state is framed by a tension or ambiguity in its relation to the upper class. On the one hand, the most important and lucrative market for professional services is the upper class. Yet, the upper class is a threat to the attainment of the ideal of universality and transcendence. It will generally be in the interest of the upper class to demand a degree of loyalty and subordination inconsistent with the professional ideal. And the more the profession as a whole is seen to be in the service of the upper class, the less plausible become the pretensions to serve universal interests. There are many strategies of accommodation to this situation (some involving exploitation of the upper class, some involving concessions to the other classes), but during some periods these strategies fail to prevent unease among large numbers of professionals and even rebellion by a few of them. Richard Hofstadter has identified the Progressive Era as a period in which professional aspirations fueled reformist politics; ${ }^{\mathbf{1 6 3}}$ the recent period of welfare legalism is another.

There is an important congruence between the expansion of the welfare state and the aspirations of the professional class. Since at least the New Deal, the national state has sought to mediate and to neutralize class antagonisms by integrating all classes into a national political process committed to universal norms. The professional class has a dual affinity for this effort: first, as an activity that respects its aspirations to universality, and second, as an alternative source of employment to the dominant class. The role envisioned for the state by the New Deal was precisely the role that Brandeis had earlier prescribed for the professionals ${ }^{\mathbf{1 6 4}}$-broker of class compromise-and the New Deal activities created a strong demand

163. R. HOFSTADTER, THE AGE OF REFORM 131-73 (1955).

164. L. BRANDEIS, BUSINESS-A PROFESSION (1926). 
for professional services. This affinity makes the professional class a potential ally of the lower classes when they make demands for the recognition and institutionalization of their interests in ways that expand the national state. The debates about the welfare system I have been discussing got underway during a period of such an alliance.

The liberal professional reformers of the 1960's sought both to expand the welfare system and to make it more responsive to the poor. They exercised their influence through the federal judiciary and the upper levels of the federal executive. From this perspective, the expanding corps of lower level service roles of somewhat ambiguous status presented them with a political choice analogous to one faced by some of the reforming monarchs of modern Europe. ${ }^{165}$ The choice is between professionalizing and proletarianizing strategies of transformation of the state. In the professionalizing strategy, the reformer creates an organizational structure designed to foster autonomous, responsible activity by people socialized in the reformer's own perspective; in the proletarianizing strategy, the reformer creates an organizational structure designed to subject subordinates to her direct control. The appeal of the professionalizing strategy is that it promises to overcome some of the deficiencies of Weberian bureaucracy as an instrument of control and, by extending the reformer's own mode of life and work, to create valuable allies for her. The disadvantages are, first, that if the strategy fails to inculcate the reformer's perspective, organizational autonomy may be used in ways that will frustrate her ends; and, second, that the expansion of professional status dilutes the exclusivity of the positions and perhaps the privileges of the reformer and her present allies. Thus, one explanation for the embrace of the proletarian strategy by the liberal reformers of the 1960's is that downward professionalization might have seemed to pose unacceptable risks to their own positions. ${ }^{186}$

165. See R. Wortman, The Development of a Russian Legal Consciousness (1976).

166. For the social workers the choice of reforming strategies involved distinctive considerations. On the one hand, the social work profession had long claimed public assistance as its province and had prescribed the integration of counseling and financial assistance. This position was premised on the notion that the personal problems of the poor were a function of their material condition. This premise had in turn inspired the view, traditional with an important segment of the profession, that the distinctive concerns of the profession were linked to the goals of redistributive social change. See Chambers, An Historical Perspective on Political Action vs. Individual Treatment, in PERSPECTIVES ON SOCIAL WELFARE 89-106 (P. Weinberger ed. 1969); Towle, supra note 15. On the other hand, financial eligibility tasks were the aspect of social work regarded as least prestigious and least integrated into the profession's academic paradigm, which, since the 1920's, has been drawn from psychology. Thus, for the social workers, the political compromise represented by the proletarianization strategy had a special significance. The profession retreated from its general redistributive political goals, ceded its influence over public assistance, and gave up the project of expanding downward. In return, it strengthened its claims to elite status by disencumbering itself of the tasks that were least prestigious and most difficult to rationalize in terms of its academic paradigm and by limiting its claims to a smaller, more clearly bounded segment of the public work force. Cf. Wyers, Whatever 
A related explanation looks at the problem from the perspective of the lower-tier public work force. The roles this group occupies are not entirely the creatures of elite professionals; the workers themselves have participated in designing them. The choice between professionalizing and proletarianizing strategies of elite reform correspond to a choice between strategies of worker politics.

For the workers, the professionalizing strategy would have involved pursuit, not only of material reward and personal comfort, but of a part in interpreting the purposes and structure of the programs they administered. It would have involved attempts to interpret the public purposes of the programs in ways that linked workers' interests with the interests of the beneficiaries. It ${ }^{\circ}$ would also have involved appeals to these purposes against formality and organizational hierarchy. The most notable illustration of such a strategy in the recent history of the American welfare system is the one through which the Social Security ALJs (formerly "hearing examiners") have transformed themselves since World War II. The ALJs have long been a class-conscious group, politically active in support of reforms to increase their organizational autonomy and the status, reward, and educational requirements of their job. Their activity has been particularly vigorous in recent years-including a series of lawsuits against the Social Security Administration in opposition to its efforts to formalize eligibility criteria, to prescribe job performance in detail, to impose productivity standards, and to use reversal rates and quality control data for personnel purposes. In the course of these efforts, the ALJs have appealed to the notions of legality and organization of the opposed vision in a way that links their own interests with those of beneficiaries. They argue that autonomy and professional status are necessary for them to perform their duty to enforce the rights of claimants. Understanding this duty to require a complex, particularized judgment, they assert that its performance is compromised by hierarchical supervision, which is inevitably less sensitive to the needs of the particular case and undermines devotion to the goal of justice to the individual client. ${ }^{167}$

Happened to the Income Maintenance Line Worker?, 25 SOC. WORK 259 (1980) (ambivalent account of separation suggesting tradeoff between profession's broader political goals and security of professional status).

167. See Scalia, supra note 149, at 66; Macy, The APA and the Hearing Examiner: Products of a Viable Political Society, 27 FED. B.J. 351, 352-94 (1967); SUBCOMM. ON OVERSIGHT OF GOVERNMENT MANAGEMENT, supra note 110; SUbCOMM. ON SOCIAL SECURITY, H. COMM. ON WAYS \& MEANS, SOCIAL SECURITY ADMINISTRATIVE LAW JUDGES: SURVEY AND ISSUE PAPER 1-3, 76-84, $111-$ 17 (Comm. Print 1979).

The style of worker politics that links interests of the worker in autonomy and participation with the interests of the beneficiaries of their work has been legitimated by the courts in cases involving professional litigants. These decisions infer rights in the professionals from laws designed to protect the beneficiaries of their work. See Nash v. Califano, 613 F.2d 10 (2d Cir. 1980) (inferring right of "decisional independence" allowing ALJs to challenge administrative supervisory and productivity 
The competing option of worker politics, the proletarian strategy, involved retreating from goals other than material reward and personal comfort. It involved a compromise with hierarchy in which formality was embraced as a shield against the demands of superiors. In this compromise, the workers relinquished their claims to participate in interpreting the goals of the program in return for a guarantee of some autonomy in pursuing private and material goals. Instead of developing the kinds of work protest exemplified by the ALJs based on appeals to program purposes, they fell back on conventional forms of protest such as strikes and slowdowns that disrupted the programs in ways that hurt beneficiaries. In effect, they exchanged the possibility of solidarity with claimants for the option of holding the interests of claimants hostage to their private demands.

To the workers, the professional strategy held the promise of a nobler and more satisfying life at work and of political solidarity with a wider segment of the society. But it was also a riskier strategy. It was a strategy that, if implemented broadly, would have made much greater redistributive demands on the society. And it was a strategy that would have depended on alliances with professionals and poor people from whom many of the new service workers were divided by ethnicity, education, and status, and whose reliability they might well have suspected. ${ }^{\mathbf{1 0 8}}$

From the point of view of the liberal reformers' goal to make the system more responsive to the poor, the proletarian strategy had severe drawbacks. The dominant vision obscured the difficulties of translating influence over the upper levels of the system into control of a lower-tier work force alienated from the purposes of those at the top. Moreover, the liberal strategy depended on liberals retaining influence over the upper levels. When in fact liberal influence waned and control passed to conservatives relatively indifferent to beneficiary interests and more intent on curbing expenditures, the proletarian strategy was easily co-opted for quite different purposes. (To be sure, the proletarian strategy has some of the same disadvantages as a means of controlling expenditures that it has as a safe-

controls); cf. Griswold v. Connecticut, 381 U.S. 479, 481 (1965) (inferring right of medical professionals to challenge restrictions on practice from patients' privacy rights).

168. Thus, while the interpretation based on social structure sees admininistrative reform as in part a response to the economistic orientation of the work force, the political interpretation sees the economistic orientation of the work force as in part a response to administrative reform. The difference lies in the extent to which one sees the way people view their interests in work as given on the one hand or as a matter of politics on the other. My political interpretation of worker politics was inspired by conversations with workers in Massachusetts during 1979-1981. It does not purport to be anything more than a speculative hypothesis.

For an account of a strike involving an unsuccessful attempt by welfare workers to ally themselves with recipients and professionals, see Weber, Paradise Lost: Or Whatever Happened to the Chicago Social Workers?, in Collective BARGaining IN GovernMENT 163-77 (J. Loewenberg \& M. Moskow eds. 1972). 
guard of beneficiary interests, but the political liabilities of the alternative professionalizing strategy would have seemed even greater to the conservatives than to the liberals.) As the conservatives implemented the strategy in a way that reallocated enforcement resources away from beneficiary interests, its adverse consequences to recipients were exacerbated.

The course of administrative reform paralleled in some respects the larger political process by which broad segments of the working class came to see their interests as in conflict with those of the beneficiaries of welfare expansion, and by defecting from the progressive constituency of the Democratic Party, brought the expansion to a halt. ${ }^{169}$ Much of the expansion of the 1960's took the form of institutional structures designed to link the federal government with the urban poor while bypassing state and local governments with strong working class representation. ${ }^{170}$ For the most part, the expansion was financed through fiscal policies that a broad segment of the working class came to see as burdening them unfairly. ${ }^{171}$ In one respect, the failure of administrative reform mirrors the failure of the broader program of welfare expansion: in each case, the ambitions of the liberal reformers were thwarted by the tendency of their program to alienate the working class.

If one adopts this political explanation of recent welfare jurisprudence, then the future prospects of the opposed vision would seem to depend on political factors, in particular, on the possibilities of reestablishing the New Deal alliance of professionals, workers, and the poor. From this perspective, an interesting feature of the opposed vision is its capacity to link the interests of the public work force in dignified, satisfying working conditions with the interests of the poor in dignified, responsible treatment by the welfare state.

\section{The Ambiguity of Professional Culture}

There is a further objection to the opposed vision as an ideal of public administration. This objection focuses, not on the premise of exclusivity, but on the premise of universality. It denies that the public culture of the professional class has been or could be anything but an expression of the contingent views or interests of the professionals themselves or their allies or patrons. Although this objection rests on a powerful critique of professionalism, it remains to be seen whether it can be maintained against a

169. See F. Piven \& R. Gloward, Regulating THE POOR 348-410 (1971); D. Moynihan, MAXIMUM FeAsible Misunderstanding (1969).

170. See Musgrave, Theories of Fiscal Crisis: Notes on Fiscal Sociology, in 1983 BRookings PAPERS ON ECON. ACTIVITY 361, 383-88.

171. See Burnham, The 1980 Earthquake: Realignment, Reaction, or What?, in THE HIDDEN ELECTION 98-140 (T. Ferguson \& J. Rogers eds. 1981). 
version of professionalism that dispenses with the premise of exclusivity. Most contemporary critiques of professional culture present an ambiguity. They both attack the culture and rely on it. This is particularly so of critiques that explicitly adopt the professions' norms in order to demonstrate how their members have betrayed them. ${ }^{172}$ Even critics who attack the structure of professional doctrine often do so in order to transform rather than repudiate it. ${ }^{173}$ And the more uncompromising critics who deny any normative status to professional doctrine have yet to show that they are capable of a plausible programmatic discourse that escapes reliance on the practices they reject.

There is a parallel ambiguity in critical accounts of professional practice and organization. On the one hand, the professions, even in their compromised state, provide evidence of the possibility of universalistic and altruistic commitment in public life and of autonomy and responsibility in work. On the other hand, they seem to institutionalize and rationalize illegitimate privilege and domination.

The case for the opposed vision suggests that the implausibility of the professional project lies less in its aspirations to universality than in the premise of exclusivity. This suggestion depends on at least two conditions. First, the tendency in the legal professional culture to criticize and transform hierarchical social relations in the name of the ideals of efficiency, freedom, and fairness would have to be developed even in the face of severe social strains; the countervailing tendency to qualify and sublimate these ideals in the name of social stability would have to be muted. ${ }^{174}$ The less the culture feels bound to defer to the constraints of social hierarchy, the more plausible become its claims to be more than an apology for that hierarchy. Second, downward professionalization would have to mean, not simply exposure or indoctrination of new recruits in the currently prevailing doctrines of the professions, but the downward extension of the social circumstances associated with the limited but significant amount of trust that is currently accorded professionals: education, reward, status, collective work experience, peer culture, and work roles incorporating autonomy and responsibility. Expanding the boundaries of the professional class in this way would affect the development of professional doctrine. There is no guarantee that such development would vindicate the aspiration to universality. The hope that it would is grounded in the notion that the larger the range and number of people who participate directly in the professional culture (and the less differentiated the culture becomes from

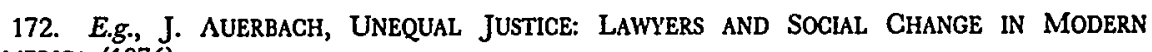
AMERICA (1976).

173. See Unger, The Critical Legal Studies Movement, 96 HARV. L. REV. 561, 576-83 (1983).

174. Id. 
its surroundings), the stronger become its claims to universality.

The basic jurisprudential questions raised by the critique of the dominant vision turn on this possibility. The answer to the questions of value and trust and the response to the deficiencies of the Weberian vision of legality and organization-the problems of communication, supervision, alienation-all turn on some variation of the principle of social order through participation in a common culture. ${ }^{175}$ This response to the deficiencies of Weberian formality and bureaucracy has been well known to American legal and social thought throughout this century. But lawyers have tended to mistake this theoretical insight for a practical achievement. They have alternated between the mistaken view that their own normative culture is shared throughout the society and the vain hope that the limitations of a culture common only to their own class could be cured through the readmission of formality and bureaucracy.

In fact, the solution of the common culture has never been anything more than a political prospect. The downward professionalization of public administration is a reform inspired by this prospect.

\section{Conclusion}

The opposed vision of welfare administration could be implemented in many ways at varying levels of ambitiousness. For example, one modest reform would involve the abolition of the AFDC Quality Control system and its replacement with an expanded system of quasi-adjudicatory review. Review for all purposes would be superintended by an expanded corps of hearings officials. ${ }^{178}$ Two changes in current practice could be made to remedy the problems that arise from the current hearing system's dependence on recipient initiation. First, in addition to cases initiated by recipients, review of a representative sample of cases could be administratively triggered. ${ }^{177}$ Centrally triggered cases would be reviewed by an auditor and by either an ombudsman-type official charged with protecting the claimant's interests or a representative of the claimant's choosing. If the reviewers disagreed with each other or the worker who made the initial decision, the disagreement could be resolved by decision at a hearing in which all participate. Second, review could also be triggered by eligibility workers who disagreed with their supervisors about any eligibility de-

175. See Fuller, Human Interaction and the Law, in THE RULE OF LAW (R. Wolff ed. 1971).

176. The proposal contemplates that the hearing officers have a degree of organizational autonomy and professionalism comparable to the Social Security ALJs or the hearing officials in the more professionalized state appeals systems, such as that of the Massachusetts Welfare Department. Substantial reform would be required in many state systems to attain this condition.

177. For a discussion of one method of triggering cases for review, see J. MASHAW, C. GOETZ, F. GOODMAN, W. SCHWARTZ, P. VERKUIL \& M. CARROW, supra note 123. 
cision. There could be selective publication of hearing decisions and the workers would be taught to regard adjudicatory decisions as precedent to be followed in similar cases.

From the perspective of the opposed vision, this proposal has several virtues. It shifts a major part of the supervisory process to forums in which the contingencies of the particular case can be explored, in which both claimants and workers can participate and confront the decisionmaker, and in which the decisionmakers understand their roles as involving responsibility to both claimants and to the public. It involves a modest expansion in the part of the system that most closely approximates the ideal of the opposed vision (an expansion that would be accomplished by a shift of resources from the present quality control system). ${ }^{178}$ Most importantly, it narrows (if only slightly) the gulf between regular eligibility work and the privileged process of review. By increasing the worker's participation in the review process and by prescribing that the worker attempt to apply the doctrine developed in that process to initial decisions, it encourages the worker to view the review process, with its commitment to complex judgment and respect for the claimant, as an integral extension of routine eligibility work. The more modest ambition of the reform is to increase the control of review procedures structured in accordance with the opposed vision; the less modest ambition is to change, however marginally, the way the eligibility workers view their own work and interests

178. An important issue that can only be mentioned briefly here concerns the extent to which the opposed vision depends on adversary representation. If the efficacy of the decisionmaker's role in the opposed vision requires adversary representation, then the applicability of this role to the task of deciding welfare claims in a non-adversary context would seem questionable. I think the opposed vision depends on adversary representation only to a limited extent.

Those who assert that adversary representation is essential presume that there is a high danger that the decisionmaker will have preconceptions or interests adverse to the claimant. See J. HANDLER, supra note 24 , at $3-25$. The argument above suggests that this danger is not inevitable, that it is a function of the way decisionmakers are recruited and socialized and the way their roles are structured. In particular, the argument suggests that the danger could be reduced most effectively through downward professionalization. On the other hand, if my argument is wrong, it is not at all clear that adversary representation can provide a more satisfactory response to the danger. The partisans of adversary representation have never been able to show that it overcomes bias, rather than simply introducing new biases or confusion; their argument rests on faith that opposing biases neutralize each other through some mechanism they cannot explain. See Damaska, Presentation of Evidence and Factfinding Precision, 120 U. PA. L. REV. 1083, 1091-95 (1975); Simon, supra note 162, at 75-83. Moreover, adversary representation displaces the problem of trust and bias onto the role of the representative; given skepticism toward the professional solution, this role may seem as problematical as that of the impartial decisionmaker. See Skolnick, Social Control in the Adversary System, $11 \mathrm{~J}$. CONFLICT RESOLUTION 52 (1967).

My illustrative reform proposes to extend adversary representation to cases other than those appealed by claimants, not in deference to the assertion that the opposed vision requires adversary representation, but in recognition of how very limited a step toward the opposed vision such a reform would be. One of the advantages of adversary representation in the current system is that it is the principal form of decisionmaking in which the system tolerates complex judgment, decentralization, and professionalism. A more ambitious and thoroughgoing reform of the initial decisionmaking role would reduce the importance of the expansion of adversary representation. 
by encouraging them to see themselves as autonomous, responsible participants in the implementation of a public program designed to alleviate individual need.

More thoroughgoing reforms would require more adventurous decentralization and redistribution of wealth, power, and status. Whether one views such reforms as serious options depends on whether one adopts the perspective of social structure or the perspective of politics on the current limitations of the system, and, from the latter perspective, the course of future political struggle over the system.

This kind of speculation about the possibilities for the progressive transformation of public administration or the welfare system may seem hopelessly utopian in a time when conventional perceptions about the range of political possibility seem steadily narrowing. But to write off such possibilities is to abandon hope for the vindication of our most ambitious and most plausible notions of the ideal of law. 